\title{
基于树枝状聚合物构建的核酸载体研究进展
}

\author{
张 薇 ${ }^{a, b}$ 徐妮为 ${ }^{c}$ 姚子健 $*, b$ 李 宽 ${ }^{b}$ 朱 ${ }^{b}$ \\ 陈良艳 $b$ 叶文玲 $b$ 仍维*, $a, b$ \\ ( ${ }^{a}$ 上海大学材料科学与工程学院 上海 200444) \\ ( ${ }^{b}$ 上海应用技术学院化学与环境工程学院 上海 201418) \\ ( ${ }^{c}$ 湖南中医药高等专科学校 株洲 412012)
}

\begin{abstract}
摘要 安全有效的基因载体对于基因治疗有着重要的应用价值. 相对于病毒性基因载体, 非病毒基因载体具有低免疫 原性、易于大规模生产和成本较低的特性，因而受到越来越多的关注，但是非病毒基因载体在转染效率和选择性方面 有一定的限制性. 综述了基于树枝状聚合物构建的基因载体的研究进展，包括：(i)树枝状及其衍生材料; (ii)与超分子母 体材料，如环糊精、葫芦脲结合的的树枝状聚合物基因载体; (iii)与无机材料结合的树枝状聚合物载体，如金纳米粒子、 氧化铁纳米粒子以及石墨烯等结合的树枝状聚合物构建的基因载体; (iv)功能响应性的树枝状聚合物载体，如 $\mathrm{pH}$ 响应 型、二硫键响应型、氧化还原型以及氟代化树枝状基因载体.
\end{abstract}

关键词 超支化分子; 基因载体; 树枝状分子; 基因治疗

\section{Recent Progress of Nucleic Acid Vector Based on Dendritic Polymers}

\author{
Zhang, Wei ${ }^{a, b} \quad \mathrm{Xu}, \mathrm{Niwei}^{c} \quad$ Yao, Zijian ${ }^{*, b} \quad \mathrm{Li}, \mathrm{Kuan}^{b} \quad \mathrm{Zhu}^{b} \mathrm{Yu}^{b}$ \\ Chen, Liangyan $^{b} \quad$ Ye, Wenling ${ }^{b} \quad$ Deng, Wei ${ }^{*, a, b}$ \\ ( ${ }^{a}$ School of Materials Science and Engineering, Shanghai University, Shanghai 200444) \\ $\left({ }^{b}\right.$ School of Chemical and Engineering, Shanghai Institute of Technology, Shanghai 201418) \\ ( ${ }^{c}$ Traditional Chinese Medical College, Zhuzhou 412012)
}

\begin{abstract}
Secure and efficient gene carrier has important application in gene therapy. Compared with viral gene vectors, non-viral gene vector has attracted much attention because of their low immunogenicity, easy mass production and low costs. However, they showed limited activity in transfection efficiency and selectivity. This paper reviewed recent research progress in dendritic polymers gene carriers, including (i) dendritic and derived materials, (ii) supramolecular parent materials, such as the carrier combined with cyclodextrins, and cucurbituril in multivariate and block type pattern, (iii) dendritic polymers gene vector combined with inorganic material, such as gold nanoparticles, iron oxide nanoparticles and graphene, and (iv) functional response type dendritic polymers gene vector, such as the $\mathrm{pH}$ response type vector, two disulfide response type vector, redox hyperbranched gene carrier and fluorinated dendrimers as gene vectors.
\end{abstract}

Keywords hyperbranched polymer; gene delivery; dendrimer; gene therapy

基因治疗是指将外源性的 DNA, RNA 用于治疗后 天获得性疾病，该方法已经被广泛应用于临床试验. 基 因治疗是公认的用于治疗后天以及先天性疾病(如艾滋 病、癌症、基因紊乱等疾病)最具发展潜力的治疗方 法 $^{[1 \sim 5]}$. 在基因治疗中只有一个问题需要解决: 基因的
输送 ${ }^{[6]}$. 输送基因的载体可分为病毒和非病毒载体. 病 毒载体由于破坏其自身自然的感染体系易引起变异，尽 管事例证明它很有效，但是其存在的安全隐患即免疫原 性以及可能的基因重组等都限制了其应用 ${ }^{[7]}$.

非病毒载体包括树枝状聚合物、多肽类、多糖类、

* E-mail: wdeng@shu.edu.cn, zjyao@sit.edu.cn

Received March 28, 2016; revised May 5, 2016; published online May 19, 2016

Project supported by the Shuguang Scholar Project, the National Natural Science Foundation of China (Nos. 21174081, 21601125) and the Natural Science Foundation of Shanghai City (No. 16ZR1435700).

曙光学者计划, 国家自然科学基金(Nos. 21174081, 21601125)和上海市自然科学基金(No. 16ZR1435700)资助项目. 
脂质体、阳离子聚合物和无机纳米颗粒. 它们由于安全、 易于制备、成本低而被广泛应用 ${ }^{[8]}$. 早期的病毒类基因 载体存在较多缺陷如转载能力小、耐反复感染、难以进 行生产和质量控制以及安全性低等. 而非病毒基因治疗 的出现, 可以克服病毒载体的种种限制. 但是很多非病 毒基因载体自身的生物毒性和低的生物降解性阻碍了 它们的发展 ${ }^{[9]}$. 因此缺乏高效低毒的基因运送载体成为 基因治疗的主要障碍. 大多数的阳离子树枝状聚合物包 括聚赖氨酸和聚乙烯亚胺, 虽然能够获得较高的转载 率, 但是却难以避免地对细胞产生较大的毒性, 使得其 临床应用受阻 ${ }^{[10 \sim 14]}$.

自从 Flory于 1974 年度荣获诺贝尔化学奖以来, 树 枝状聚合物(dendritic Ploymers, dendrimer)由于其独特 的结构和物理化学性质在聚合物学科领域引起人们广 泛关注, 并在最近 40 多年蓬勃发展. 树枝状聚合物是继 线形、支链形和交联聚合物以后新发展的第四类聚合物, 包括树枝分子 (dendrimer) 和超支化聚合物 (Hyperbranched polymer). 树枝形聚合物具有精确的纳 米构造, 其精确的层数与体积可由合成步骤决定. 此类 聚合物一般通过 $\mathrm{AB}_{2}, \mathrm{~A}_{2}+\mathrm{B}, \mathrm{A}_{2}+\mathrm{B}^{\prime} \mathrm{B}_{2}$, 自缩合乙烯基 聚合(SCVP)及自由基聚合等方法共价合成. 树枝形分 子是通过缩聚反应得到的, 需严格控制反应过程使其结 构具有极好的对称性, 从而得到完美状态的树枝状结构 的分子. 但这类树枝状化合物的制备和纯化具有一定的 困难, 因而限制了其广泛的发展应用. 超支化聚合物的 结构不要求很完美, 具有一定的相对分子质量分布, 并 且与树枝形分子相似，一般可采用一锅法来合成，所以 易于产业化生产. 最近部分研究者已经开始通过超分子 化学的方法来合成具有不同拓扑结构的树枝状聚合物, 这类聚合物由于具有无尺寸限制、可大量生产且重复性 好、价格低、使用简单方便、易于修饰等优点而受到广 泛关注 ${ }^{[15]}$. 自 20 世纪 80 年代以来, 树枝状聚合物的合 成方法由最初的发散法发展出收敛法、发散收敛共用法 以及固相合成法等多种合成方法 ${ }^{[16,17]}$.

树枝状聚合物具有得天独厚的分子特征(三维立体 结构)和物理化学性质, 因此被广泛地应用于构建多种 聚合物材料、纳米药物、生物材料等. 特别是在抗癌基 因载体中起到很好的抗癌治疗效果, 表现在与 DNA/ RNA 分子的偶联及与抗癌药物分子的结合. 树枝状聚 合物可以通过修饰得到不同功能响应型树枝状聚合物 基因载体，并可以和多种有机大分子、无机材料复合形 成多功能基因载体 ${ }^{[17,18]}$. 该类分子所形成的基因载体也 逐渐成为非病毒载体中的重要成员. 本文以四个章节分 别介绍了树枝状聚合物材料、有机无机化合物结合的载 体材料、超分子母体材料结合的载体材料和功能响应性
载体等材料.

\section{1 树枝状及其衍生材料}

近年来基于阳离子聚合物的非病毒转基因载体已 经取得了备受瞩目的进展 ${ }^{[18,19]}$. 多种阳离子树枝状聚合 物分子被应用于基因转载的研究中, 本文主要侧重于介 绍支化聚乙烯亚胺(polyethyleneimine, PEI)、超支化聚酰 胺胺[poly(amido amine)s, PAAs)]、聚酰胺一胺型树枝状 高分子(polyamidoamine, PAMAM)、聚 $L$-赖氨酸树枝状 化大分子 $[\operatorname{poly}(L$-lysine), PLL]、聚(醚亚胺)树枝状高分 子(PETIM)、聚丙烯胺树枝状高分子(polypropyleneimine, PPI)、三嗪类树枝高分子(triazine dendrimers)、碳硅烷树 枝状高分子(carbosilane dendrimers)、磷化树枝高分子 (phosphorus dendrimers)、紫精树枝高分子 (viologen dendrimers, VGD)以及基于氨基酸及其多肽构建的树枝 状聚合物. 此类聚合物拥有特殊的结构及纳米尺寸, 并 且在外围有大量的官能修饰位点. 该类聚合物结构具有 丰富的可修饰功能基团，提供载体的功能化和智能化修 饰的可能，因此被应用于基因载体材料. 利用树枝状聚 合物的大量外围官能团进行改性, 构建优良性状的阳离 子聚合物, 实现基因分子的转载. 氨基载量高的正电荷 树枝高分子与脱氧核糖核酸/核糖核酸的磷酸基负离子 结合, 将伸展的双链 DNA/RNA 分子压缩成纳米小球. 此种复合可以保护 DNA/RNA 分子在细胞内的分解, 利 于细胞内吞及其基因的释放(图 1) ${ }^{[19]}$.

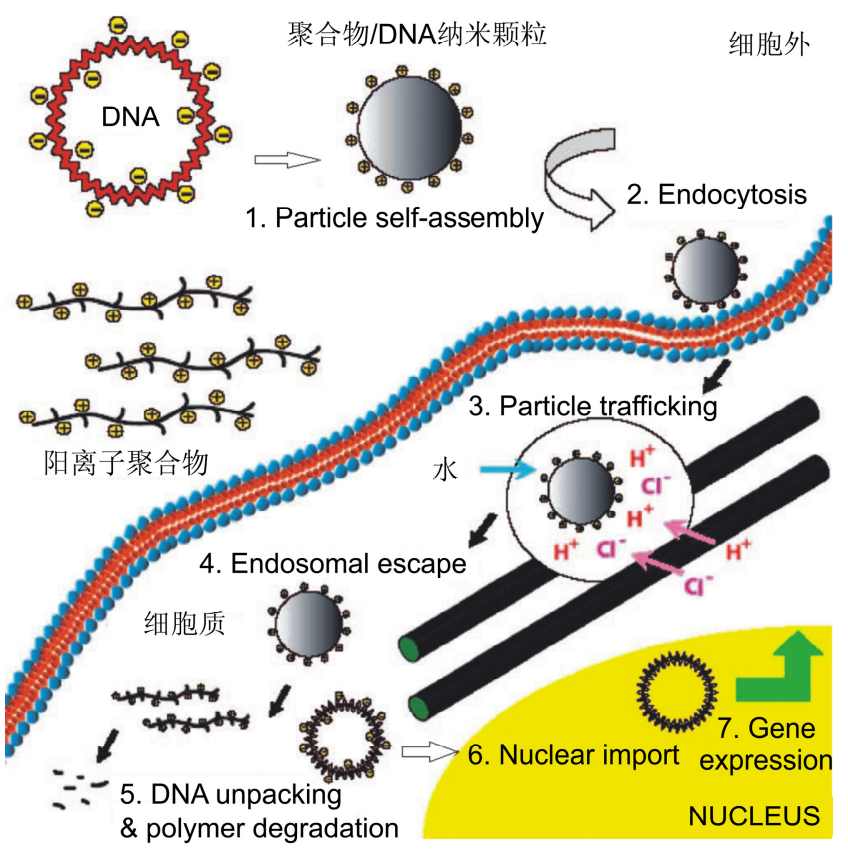

图 1 聚合物转载基因机制

Figure 1 Polymer gene transfer mechanism

Polyethyleneimine (PEI) 是一类典型的基因载体, 它 
被广泛应用于脱氧核糖核酸(DNA)、小片段干扰核糖核 酸(siRNA) 以及反式寡聚脱氧核苷酸(ODN)的转导, 并 表现出极高的转导效率. PEI 的正电荷起到质子海绵体 的作用并且对 DNA 有较好的保护. 但同时也因为其内 在的生物毒性、与体内细胞组织、血液细胞中没有特定 靶向性, 并且在血清蛋白中会自聚合, 从而限制了其在 生物体内的应用. 为了提高 PEI 的生物靶向性降低其生 物毒性, 科学家将 PEI 与多种分子(脂质体、聚合物、生 物活性分子等)结合. 引入靶向分子可以有效提高基因 的靶向传递, 实现靶向细胞的选择性转染. Carsten 等 ${ }^{[20]}$ 报道的超支化 PEI 自组装的二元或三元复合物(比如 PEI-pDNA-INS) 可以提高肺泡上皮细胞的基因传递和表 达(图2). 他们利用超支化 PEI 与质粒脱氧核糖核酸自组 装成复合物粒子, 将人胇岛素(INS) 以非共价键吸附在 二元复合物纳米粒子上, 由于肺泡支气管上皮细胞中胰 岛素受体较多, 从而达到定向转载基因并且增加基因表 达的目的; 同时胰岛素包覆后可以降低三元复合物的生 物毒性. 由此自组装形成的三元 PEI-pDNA- INS 目标复 合物为肺泡上皮细胞的后天获得性和遗传肺部疾病提 供了新疗法.

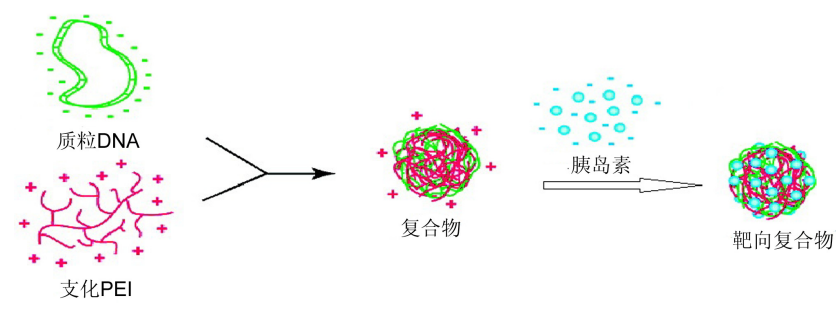

图 2 PEI 的基因载体

Figure 2 PEI gene carrier

官能团的修饰同样可以增加 PEI 基因载体的靶向 性, $\mathrm{Li}$ 等 ${ }^{[21]}$ 报道的含功能性官能团的 PEI 实现了基因的 定向转载. 他们利用经油酸修饰的吐温 85 , 经过琥珀酸
酐开环形成羧基化吐温 85 , 然后将其与低分子量 PEI(分子量为 2000)缩合形成两亲性的二元复合大分子, 该复合物与 $\mathrm{pDNA}$ 自组装形成新型基因载体 TP. 小分 子 PEI 的毒性较低, 并具有较高的转载效率. 脂质层的 存在为正电荷的 PEI-DNA 复合物的内核提供了一个电 荷屏蔽外延. 实验表明，TP 是安全有效的基因载体，特 别是在大量表达的低密度脂蛋白受体细胞中的使用, 如 HT29-DX 细胞(人结肠癌细胞株)、A549 的 DX 细胞(肺 癌细胞系)及 HepG2 细胞(肝癌组织)等.

超支化聚合物与树枝高分子相同，具有丰富的末端 官能团、三维空间结构和分子内部空穴结构, 并且在基 因转染方面展现着优异的性能. 但它在合成和纯化方面 有着显著的优势，如制备简单、可规模化生产. Wang 等 ${ }^{[22]}$ 报道了超支化聚酰胺胺(PAAs)应用于基因输送体 系. 作者通过一锅法迈克尔加成聚合，以 $N, N^{\prime}$ - 亚甲基 双丙烯酰胺和 1-(2-胺乙基)哌嗪为反应单体，通过控制 反应液 $\mathrm{H}_{2} \mathrm{O} / \mathrm{DMF}$ 的比例得到了支化度为 $0.06 \sim 0.44$ 、 数均分子量为 8300 9320 的超支化聚酰胺(图 3). 通过 对超支化高分子支化度的控制而调整其质子缓冲能力、 生物毒性以及压缩 $\mathrm{pDNA}$ 的能力. 实验结果显示聚合物 /质粒 DNA 的复合物可以高效进入细胞, 并且聚合物载 体在转染过程中停留在细胞质内. 后期他们利用 $N, N^{\prime}$ 双(丙稀酰)胱胺代替单体 $N, N^{\prime}$-亚甲基双丙烯酰胺合成 了氧化还原响应型的超支化基因载体.

对树枝状分子外围的整体修饰可以更大范围地实 现树枝高分子的改性. Narayanaswamy 等 ${ }^{[23]}$ 报道非病毒 载体可以在分子水平进行修饰，由此可得到最优化基因 载体. 他们报道了可以进行有效基因转载的聚(醚亚 胺)(PETIM)树枝状高分子 ${ }^{[24]}$ (图 4). 利用叔胺化合物为 骨架分支点, 将正丙醚连接在它们的周边, 然后再利用 伯胺分子进行末端修饰合成 PETIM 树枝状高分子. 电 子显微镜图显示, pEGFP-C1-PETIM 聚合物在对乳仓鼠

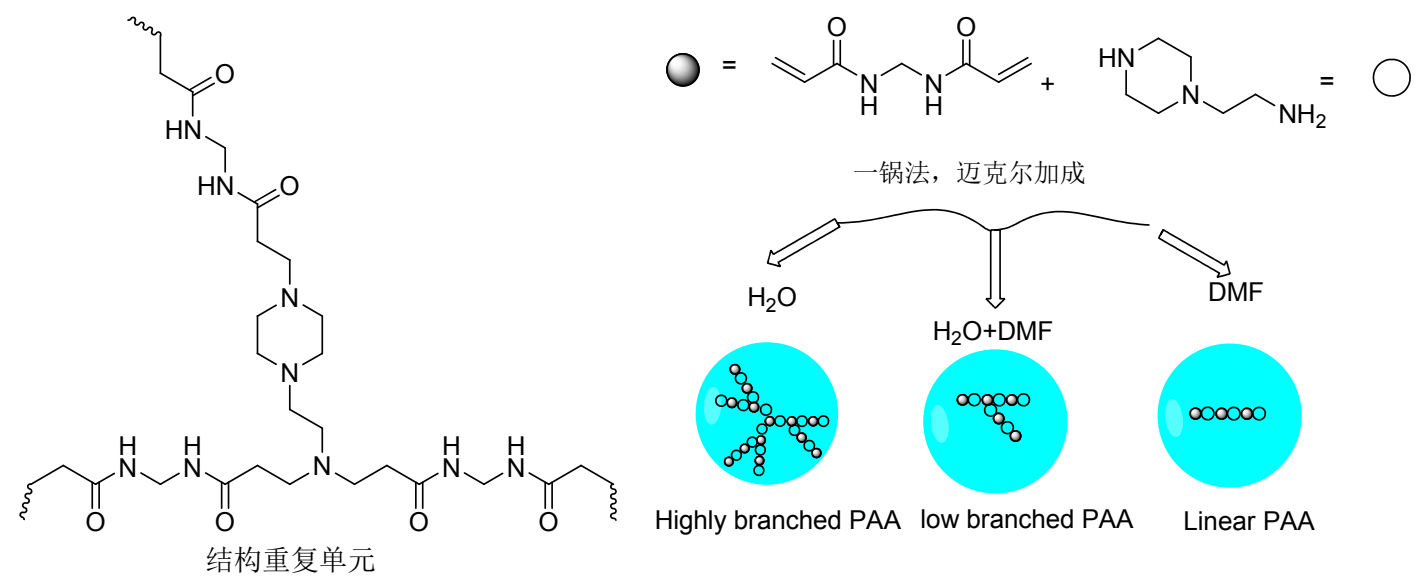

图 3 PAA 超支化基因载体

Figure 3 PAA hyperbranched polymer gene carrier 
肾细胞(BHK-21)进行转染 $8 \mathrm{~h}$ 后, 在细胞核膜外部以及 细胞核内均有聚合物的存在, 有力证明了 PETIMpEGFP-C1 聚合物可以转染到细胞浆中, 并且可以很好 脱离内涵体进行基因转染. 实验表明 PETIM 在很宽的 浓度范围均显示较低的生物毒性; 并且它可以有效压缩 质粒 DNA, 保护 DNA 免受来自内涵体的损害, 从而把 转载的 DNA 安全输送到到细胞核内.

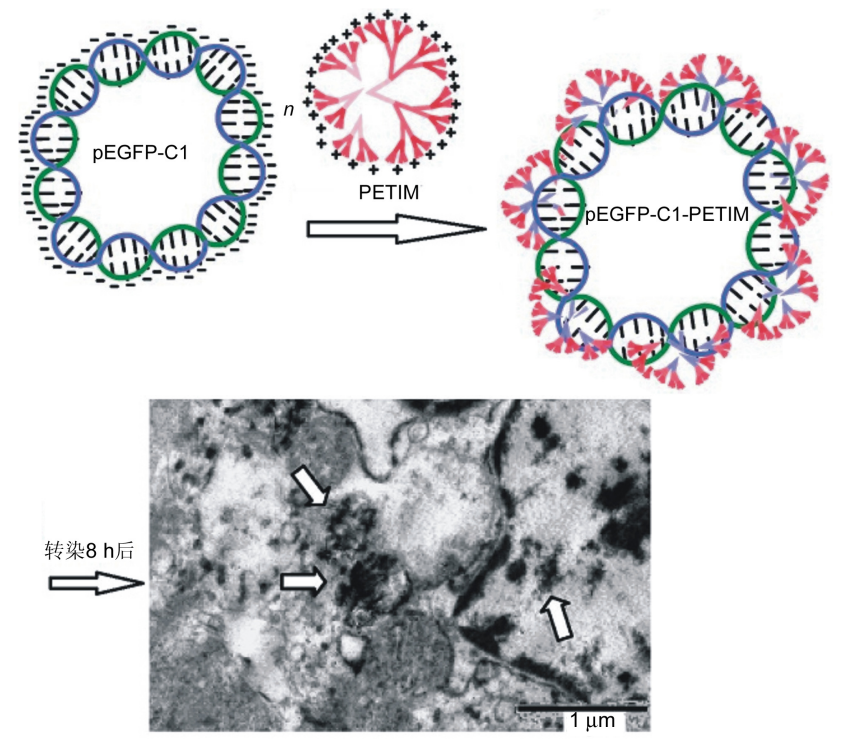

图 4 PETIM 树枝基因载体

Figure 4 PETIM dendrimer gene carrier

与 PEI 超支化分子相同, PAMAM 树枝高分子不仅 可以转载基因, 并且氨基官能团可以结合药物分子组成 嵌段化合物, 此外其本身也具有苂光 ${ }^{25]}$. 但该大分子的 生物毒性限制了其在药物基因转载上的应用 ${ }^{[26,27]}$. PAMAM 树枝状高分子通过共轭萗酰亚胺基团的取代反应 进行改性, 如它结合壳聚糖(CTS)后主链共轭物的水溶 性增加, 并且可与质粒 DNA 复合形成球形颗粒. CTS-PAMAM 的共轭/质粒 DNA 复合物的转染效率明显 高于未改性的壳聚糖和 PEI, 同时具有较低的 N/P(树枝 状分子中的一级胺和二级胺/DNA 或者 RNA 中的磷 酸比值). 同时研究人员对合成的 CTS-PAMAM 复合物 进行 DNA 的络合, 体外细胞毒性, 体外转染 HeLa 细胞 (子宫颈癌细胞)和血液相容性进行了研究. 结果表明, 壳聚糖改性后的树枝状共轭物即使在高浓度 (300 $\mathrm{mg} / \mathrm{mL}$ ) 也表现出优异的 DNA 复合性, 低毒性以及血液 相容性. 后期他们发现 $N$-酰化壳聚糖修饰的 PAMAM 也表现较好的转染. 因此壳聚糖分子的共轭树枝状分子 CTS-PAMAM 可用作安全的非病毒基因载体.

聚乙二醇 PEG 具有良好的水溶性, 并与许多有机 物组分有良好的相溶性. 正是由于 PEG 的优良兼容性 使得聚乙二醇在阳离子聚合基因载体中得到广泛应用.
Tamara 等 ${ }^{[28]}$ 报道了三嵌段聚合物即聚酰胺-胺和聚(乙 二醇)-多聚赖氨酸(PAMAM-PEG-PLL) 纳米载体的设 计、合成以及其转导 siRNA 的研究(图 5). 该基因载体 解决了细胞中 siRNA 转导中难以被细胞摄取、易于被内 涵体吞噬、易于降解等问题. 三元复合物集三个聚合物 的优点于一体: (1)聚酰胺团树枝状高分子作为质子海绵 在内涵体逃逸和在细胞质中运载 siRNA 发挥了至关重 要的作用; (2) PEG 作为连接分子稳定和保护血浆中的 siRNA 核酸; (3) 多聚赖氨酸(PLL)上的胺基阳离子可以 通过静电反应和带负电的 DNA 结合. 实验结果表明 PAMAM-PEG-PLL 可以很好地与 siRNA 结合, 可以有 效地被肿瘤细胞吸收, 并且可以诱导释放 siRNA 上的靶 向基因 Bcl-2B(淋巴细胞瘤-2 基因).

\section{0} 聚酰胺-胺 聚乙二醇聚L-赖氨酸 干涉RNA

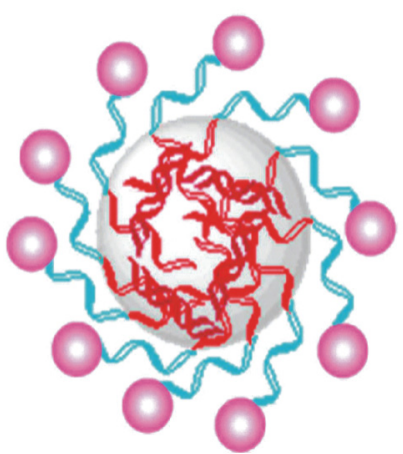

图 5 聚 $L$-赖氨酸树枝状化嵌段基因载体

Figure 5 PLL multiblock gene carrier

阳离子聚合物/DNA 复合物很容易在人血清中沉 降, 被各种生物酶分解, 如何提高其血清的抵抗力、生 物可降解性以及无毒转染机制备受科学家关注. Zhang 等 ${ }^{[29]}$ 合成了以 PPI 二代树枝高分子为核心的 MP-G-PPI 多臂基因载体(图 6). 作者利用内核 PPI 上的氨基修饰上 聚( $L$-谷氨酸)(PLG)后, 再接枝低代 PPI (G1.0 或 G2.0)形 成环绕式多臂支链. 由于 PLG 支臂可生物降解且毒性 低, 而且 PPI 球状结构外围的小分子 PPI 可以很好地保 护压缩 DNA, 因此应用其转染 DNA 进行基因治疗也取 得了很好的效果. 该类载体的电势(zeta potentials)可达 到 $42 \sim 44 \mathrm{mV}$ ，这种聚合物能够与质粒 DNA 复合从而 得到稳定的带正电荷的粒径为 $111 \sim 219 \mathrm{~nm}$ 的纳米颗 粒. 用透射电子显微镜(TEM) 可观察到 MP-G1.0 PPI/ pDNA 相互作用形成的球形颗粒状复合物. 对比不同分 子量和不同 PEI 载体结构的转染 siRNA 基因治疗, 结果 表明其达到了 Lipofectamine 2000 (L2k) 同等的效果.

含三嗪骨架的高分子利用胍胺上氮可以与 DNA 上 
核酸碱基(胸腺嘧啶、尿嘧啶)形成相互交联的氢键实现 对基因的转载. 但是含三嗪骨架的高分子如聚(乙烯基 三嗪 4,6-二氨-1,3,5-三嗪)基因载体的水溶解性差和转导 效率低等缺点使其在临床应用中受到限制. 而 Wang 等 ${ }^{[30]}$ 将三嗪分子通过简单易行的方法修饰在树枝分子 PAMAM 上, 形成水溶性三嗪类树枝高分子(Triazine dendrimers)基因载体. 三嗪修饰的树状大分子可以高效 地将相关调亡诱导配体基因(TRAIL, related apoptosis inducing ligand gene therapy)和增强功效蛋白(EGFP)的 绿色荧光基因转载到肉骨瘤细胞中(成人肉骨瘤 MG-63 细胞株). 肉骨瘤是一种常在青少年中发展的恶性骨肿 瘤. 尽管近年来在治疗水平上有所提高, 但是仅有的 5 年生存率让患者的治愈率降低很多. 此类基因载体与 TRAIL 质粒进行复合, 对荷瘤小鼠进行注射治疗, 对应 的基因表达蛋白质含量明显提高, 有效抑制肿瘤的生 长, 肿瘤重量远远小于对照组, 达到基因治疗的效果, 具有临床应用的价值, 有望成为该病变的治疗手段. Shao 等 ${ }^{[31]}$ 进一步通过表面修饰树枝状大分子 PAMAM 合成了一系列的表面富含胍胺分子 2,4-二氨-1,3,5-三嗪 (DAT) 的树枝状大分子(G5-DAT55), 并且所合成树状大 分子具有显著的转染效果且细胞毒性低(图 7). 在非洲
绿猴肾成纤维细胞(COS-7)中进行三维细胞培育, 结果 表明, G5-DAT55 在对 EGFP 基因转染试验中, 其效率优 于代表性转染试剂 Lipo 2000 和 bPEI(分子量: $25 \mathrm{KD}$ ). 并且 G5-DAT55 表现出更高的绿色苂光蛋白在 3D 细胞 球内表达的能力. 互补的多个氢改性配体与核酸碱基的 键合作用在基因转染的成功中起着至关重要的作用. 氢 键调制策略在阳离子聚合物应用非常广泛, 在设计高效 转染和减少细胞毒性基因载体上有突出贡献. 后期他们 将利用这一策略合成一系列高效率和低细胞毒性的高 分子基因载体.

由于硅原子的特殊性质，与其他的树枝状高分子相 比，含硅的树枝状高分子具有显著的多样性，同时具有 含硅化合物的许多优异性能，如低的玻璃化温度、低的表 面能等. 根据不同的生物应用，可将适当的官能团键接 于有机硅树枝状高分子上，赋予了树枝状高分子新的功 能. 研究表明碳硅烷超支化分子可以很好地转载释放寡 核苷酸(ODNs)与小片段干扰核糖核酸(siRNA). Martínez 等 ${ }^{[32]}$ 利用酞酰亚胺为起始原料合成了不同支化代数的碳 硅烷树枝高分子，并且在大分子外围进行氨基甲基化修 饰(图 8). 研究表明树枝状化合物表面带有正电荷的氨基

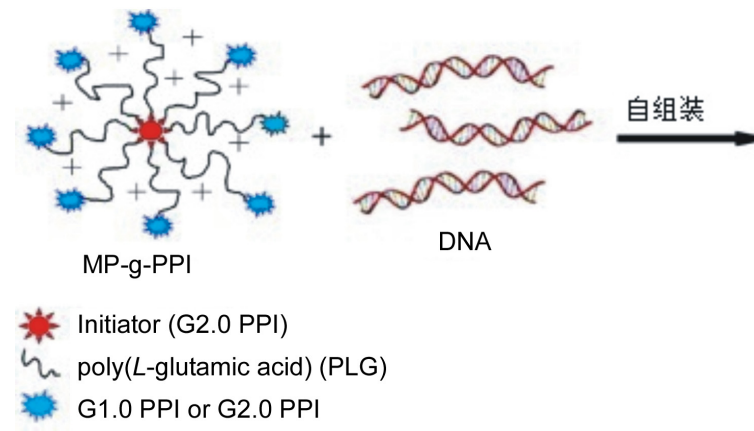

图 6 聚丙烯胺树枝状基因载体

Figure 6 PPI dendrimers gene carrier

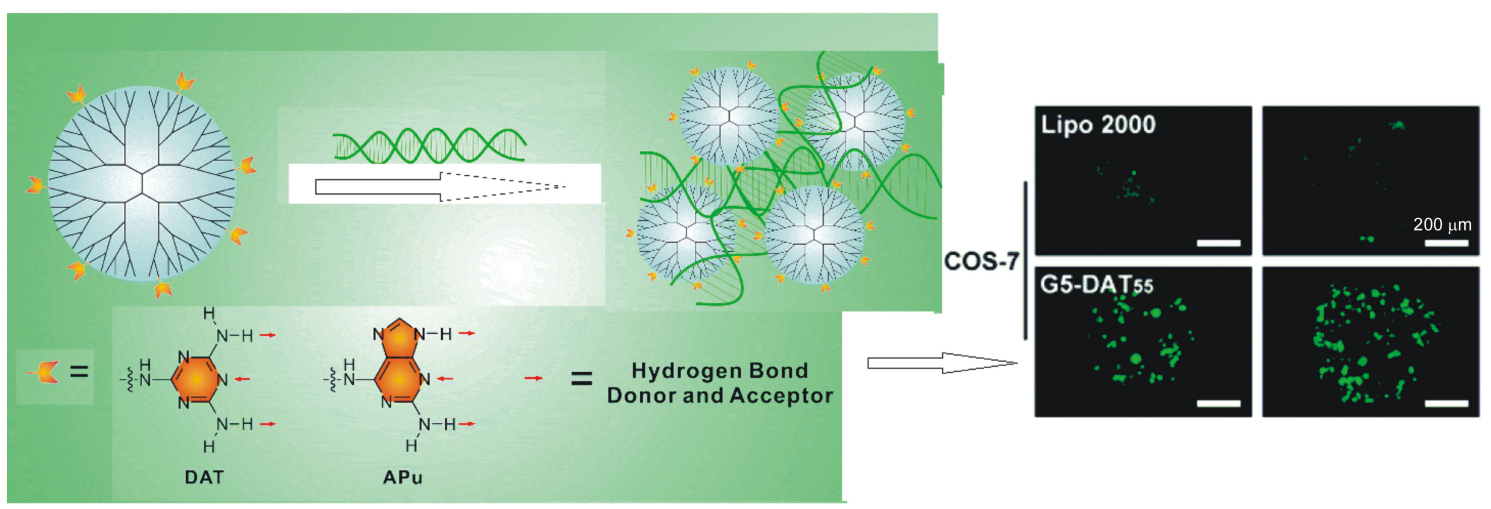

图 7 三嗪树枝状基因载体

Figure 7 Triazine dendrimers gene carrier 


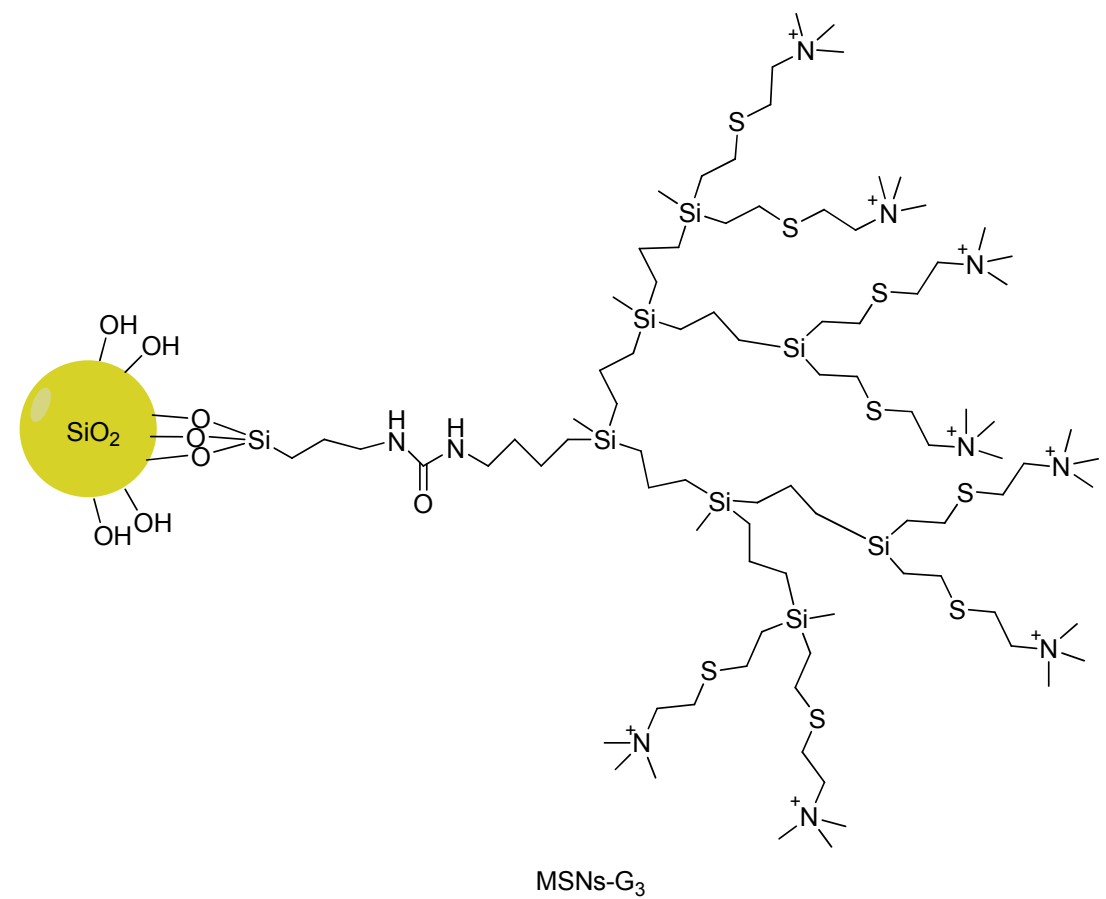

图 8 碳硅烷超支化基因载体

Figure 8 Carbosilane hyperbranched polymer gene carrier

或季铵盐具有抗菌活性. 然后将合成的阳离子三代碳硅 烷超支化分子修饰在介孔二氧化硅(MSNs)上, 并且可以 利用二氧化硅的孔径吸附相关药物分子. 该类基因载体 在转染 ODNs 过程中不影响细胞存活率, 生物毒性很小. 实验表明，其在人骨肉瘤细胞(HOS cell)的 $24 \mathrm{~h}$ 内 DNA 转载率可达到 $84 \%$, 成功取得了临床基因治疗效果.

磷化树枝状分子具备其他阳离子没有的热稳定性 (高达 $250{ }^{\circ} \mathrm{C}$ ), 并且在水中具有极佳的酸碱稳定性 $(\mathrm{pH}$ 从 3 到 12)以及树枝分子空间灵活性. 正是由于磷化树 枝状分子的特殊性质使其得到广泛的应用. Loup 等 ${ }^{[33]}$ 通过连续控制片段分子 $\mathrm{H}_{2} \mathrm{~N}-\mathrm{N}(\mathrm{Me})-\mathrm{P}(\mathrm{S}) \mathrm{Cl}_{2}$ 的生长得到 了五代磷化树枝高分子. 最后通过对末端三级胺的甲基 化修饰得到末端含 96 个胺基阳离子的五代磷化树枝状 高分子(图 9). 实验表明, 磷化树枝化末端叔胺质子化树 枝分子在 5 equiv. 核苷酸下成功实现了对血清细胞中高 效转染荧光素酶基因的转染. 此外, 它们没有毒性, 并
且在水溶液中非常稳定. 作者后期将进一步研究评价这 些新树枝状高分子在体内转染药物的性能.

紫精 $(N$-取代的 4,4'-联吡啶季铵盐)具有优良的氧化 还原可逆性及特殊的光电化学性能, 因此在光电转换、 光致变色、电致变色材料等方面有广泛的应用. $\mathrm{Li}$ 等 ${ }^{[33]}$ 合成了一系列的紫精树枝高分子(VGD), 分别利用甲 基、乙基以及胸腺嘧啶修饰，并且对这些 VCD 在基因 转染上的进行研究(图 10). 实验表明增加紫精树枝分子 重量和正电荷的数量可以提高 DNA 转染效率和 CXCR4 拮抗作用, 然而, 较高的分子量同时也增加了细胞毒性. 因此，实验表明低支化代的 VGD (G1，G2)拥有作为趋 化因子受体(CXCR4)拮抗剂和基因载体双重功能. 这种 双功能基因载体在 CXCR4 基因治疗中有突出的效果, 适用于包括癌症转移、HIV 感染和多种炎性疾病, 为未 来基因治疗提供了可能.

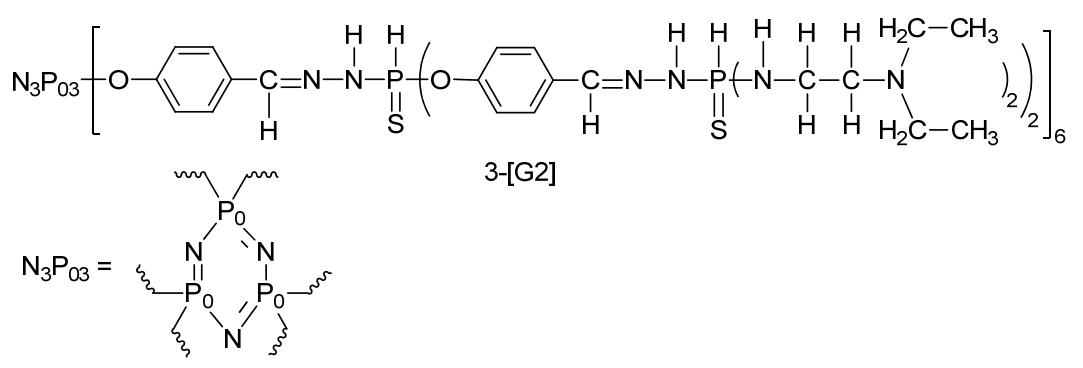

图 9 磷化树枝状基因载体

Figure 9 Phosphorus dendrimers gene carrier 


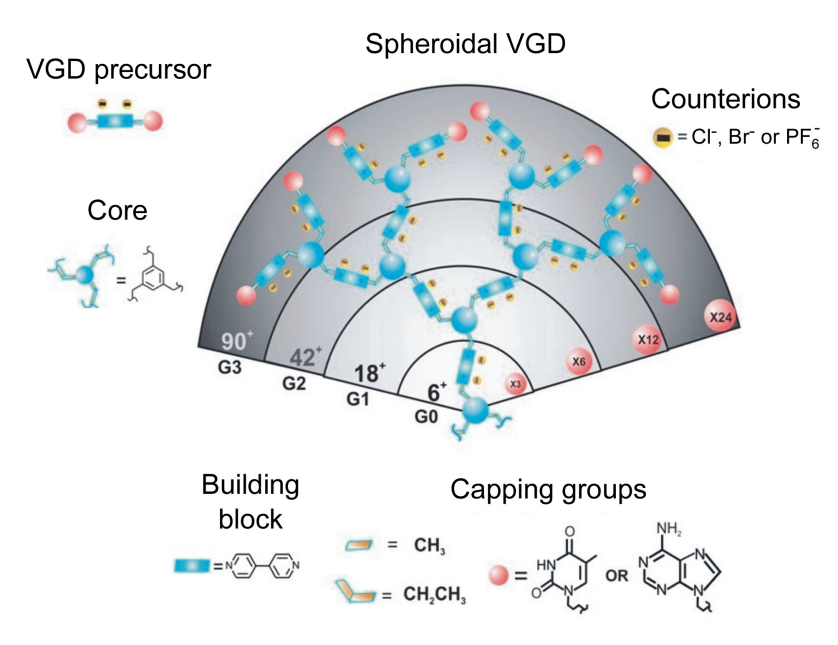

图 10 紫精树枝高分子基因载体

Figure 10 Viologen dendrimers gene carrier

利用天然氨基酸作为树枝状分子的单体不仅充分 了利用天然氨基酸的优点, 并且合成的树枝状载体毒副 作用小 ${ }^{[34]}$. Helena 等 ${ }^{[35]}$ 报道了树枝状聚酰胺一胺 (PAMAM) 结合 RGD 短肽 Arg-Gly-Asp(精氨酸-甘氨酸天冬氨酸)的新型基因载体. 聚酰胺-胺六代树枝状分子 经修饰后可控制结合上 4 个、 8 个、16 个多肽单元(图 11). RGD 多肽在细胞表面作为纤维连接蛋白受体可以 提高基因转载效率. 实验证明质粒 DNA 可以通过 RGD 中间介导与细胞表面的负电荷发生非特异性静电反应 进入骨髓间充质干细胞. Khuloud 等 ${ }^{[36]}$ 利用新型第六代 阳离子水溶性聚 $L$-赖氨酸树枝状化大分子 poly $(L-1 y-$ sine)(分子量 8149000)与疏水性化疗药物阿需素络合, 增加了亲脂性抗癌类药物的渗透性和转载效率. 而且这 个复合物在单层细胞组织、多细胞肿瘤球体 (MTS) 以 及活体肿瘤细胞里都展现了比单独抗癌药更好的渗透 性. 总的来说, 利用抗血管增生的超支化聚合物基因载 体可以提供一个合理的抗血管生成和肿瘤体内化疗的
组合疗法.

利用天然氨基酸组成的多肽同样可用于基因载体, 并且多肽倍广泛应用于在特定组织及细胞内的基因靶 向/定向转导. Bayele 等 ${ }^{[37]}$ 合成了以疏水性脂肽为核心, 外围修饰带正电荷赖氨酸的双功能超支化分子非病毒 基因载体. 脂肽结构的独特性、合成可控性和特异性以 及它们的多功能性和广泛的修饰性，使他们成为新的一 类超支化高分子基因载体. 该小组对脂肽的末端赖氨酸 进行修饰，从而形成内核疏水外围亲水的超支化载体. 实验表明, 肽的超支化分子可以在体外干扰苂光酶的 RNA 的表达. 同时在肽基础上将超支化高分子与抗癌 药物结合, 可以增加抗癌脂溶性药物在体内的吸收.

\section{2 与超分子母体材料结合的树枝状聚合物载体}

超分子通常是指由两种或两种以上分子依靠分子 间相互作用结合在一起, 组成复杂的、有组织的聚集体, 并保持一定的完整性使其具有明确的微观结构和宏观 特性. 与超分子母体材料结合树枝状聚合物得到的基因 载体可以有效地降低生物毒性、提高转染效率和增加靶 向性, 合成该类智能型载体的方法包括改变立体结构、 增加功能基团以及连接靶向分子等. 尤其是利用分子识 别能力和分子间超分子作用构建不同拓朴结构的智能 基因载体越来越受到生物化学科学家的关注 ${ }^{[38]}$.

环糊精 $(\mathrm{CD})$ 是由多个 $D(+)$-葡萄糖单元通过 $\alpha-1,4-$ 糖苷键首尾相连而成的环状化合物. 正是由于 $\mathrm{CD}$ 具有 “内疏水、外亲水” 的特殊空间结构, 使得环糊精得到广 泛的应用. Shreyas 等 ${ }^{[39]}$ 报道了基于环糊精修饰的树枝 状聚酰胺-胺的基因输送体系(图 12). 通过三-(2-氨乙 基)胺与丙烯酸甲酯为单体进行迈克尔加成聚合然后氨 解后得到末端为 48 个氨基的树枝状聚酰胺一胺, 将此化 合物与对甲苯磺酰化的 $\beta$-环糊精反应得到环糊精修饰

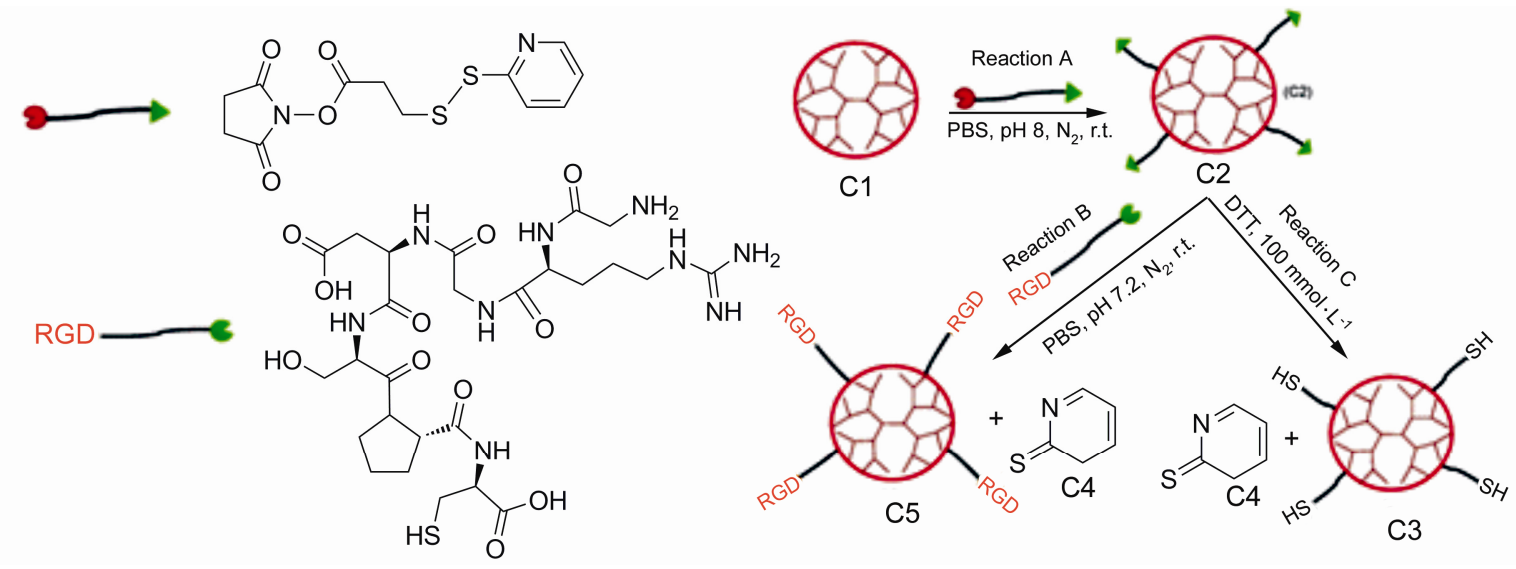

图 11 聚氨基酸基础的基因载体

Figure 11 Poly amino acid based gene vector 


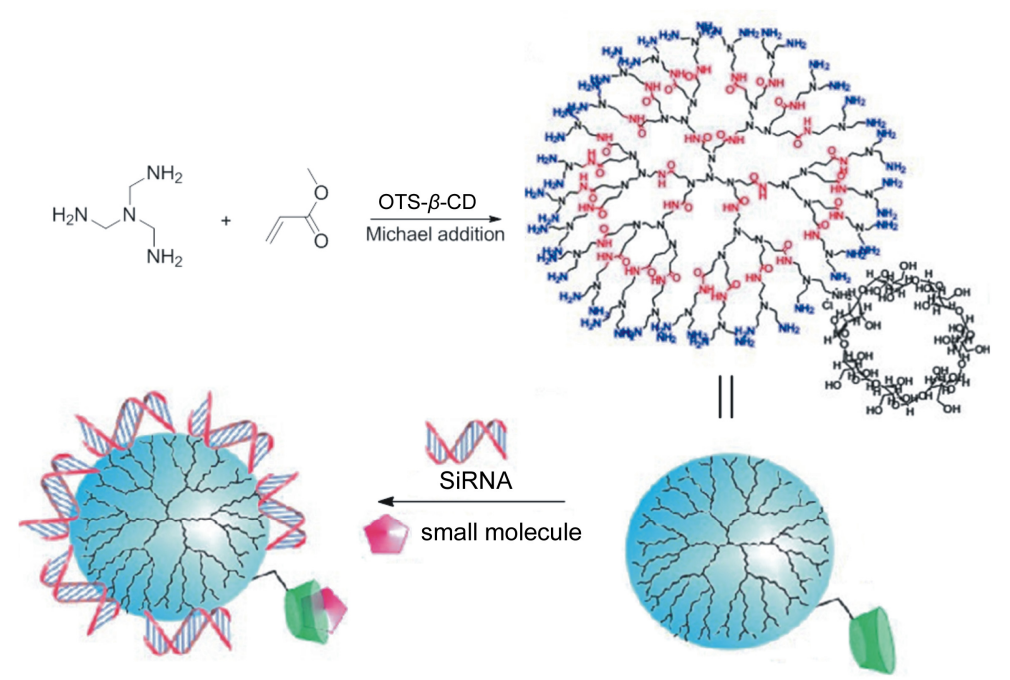

图 12 环糊精末端修饰的树枝基因载体

Figure 12 Cyclodextrin end modified dendrimer gene carrier

的树枝状分子聚合体, 实验表明环糊精的增加有助于降 低材料的毒性. 同时环糊精树枝状聚酰胺-胺具有良好 的质子缓冲能力, 能够有效浓缩 pDNA, 对外源性基因 以及疏水性药物分子均能进行高效转载. Huang 等 ${ }^{\left[{ }^{[} 0\right]}$ 利 用修饰的 PEG 2000 与 $\alpha-C D$ 反应制备了聚轮烷，再通过 相应修饰形成的 PPG1 纳米颗粒基因载体可与 $\mathrm{pDNA}$ 形 成稳定的复合物胶体, 该 PPG1 超分子/质粒 DNA 复合 物(约 $100 \mathrm{~nm}$ 直径)经过了 256 倍稀释后还是非常稳定, 并且保持其初始尺寸和分布; 体外细胞实验表明它在人 胚肾细胞中运载 pDNA 主要通过小胶囊依赖的途径, 而 不是 PEI(分子量为 $25 \mathrm{~K}$ ) 依赖网格蛋白途径.

除了天然环糊精构建的基因载体外, 很多人工合成 的超分子母体材料也被应用其中, 并且具有尺寸可控, 自由度更大等优点. 葫芦嫝分子是一种桶状的环状化合 物. 它的空腔是疏水的, 而且两端开口, 空腔两头比较 小、中间很大, 可以包结有机分子. Lim 等 ${ }^{[41]}$ 报道的葫芦 嫝(CB) 是一个由 6 个甘脲单位的亚甲基桥相互作用组成 的大笼状化合物(图 13). 他们利用 CB 与 PPI-DAB 树状 分子(1,4-二氨基丁烷, 二聚)三代支化物以及 DNA 自组 装形成三元复合物. PPI-DAB 和葫芦脲 $(\mathrm{CB})$ 被认定为一 例完全组装的基因传递载体, CB 与 PPI-DAB 通过多个共 价键相互作用, DNA 与 PPI-DAB 通过静电内在反应生成 三元复合物. 动态光散射数据表明, 其粒径的大小和分 布在 150 210 nm 内. 苂光结果表明三元络合物中 $\mathrm{CB}$ 和 PPI-DAB 是定量结合的. PPI-DAB/CB 复合物的细胞毒性 相对较低并且能够在哺乳动物细胞内高效转染基因.

\section{3 无机材料结合的树枝状聚合物载体}

无机材料具有很多优异的特性(比如热辐射性, 磁
性等), 特别是无机纳米颗粒, 往往具有宏观所没有物 理化学性能. 纳米材料指的是纳米结构按一定方式堆积 或一定基体中分散形成的宏观材料. 无机纳米结构为至 少一维尺寸在 $1 \sim 100 \mathrm{~nm}$ 区域的结构, 它包括纳米粒 子、纳米纤维、纳米薄膜、纳米块状和纳米晶等. 树枝 状分子树枝状聚合物与不同无机物的结合，赋予树枝状 基因载体新的生命力 ${ }^{[42]}$.

纳米金即指金的微小颗粒，其直径在 $1 \sim 100 \mathrm{~nm}$, 具有高电子密度、介电特性和催化作用，能与多种生物 大分子结合，且不影响其生物活性. 引入靶向分子可以 有效提高基因的靶向传递，实现靶向细胞的选择性转 染. Shi 等 ${ }^{[43,44]}$ 报道了利用叶酸分子修饰后可作为靶向 基因载体的金纳米-支化粒子(Au DENPs-FA). 它与质 粒 DNA 可自组装成聚合物, 凝胶阻滞实验、动态光散 射和 Zeta 电位实验均表明其有效压缩质粒 DNA 形成的 复合物具有小尺寸且表面带正电荷(图 14). Au DENPsFA 的基因转染实验表明其可高效和特异地在 Hela 细胞 上进行转染荧光素酶基因(Luc), 并且可以增强绿色荧 光蛋白(EGFP)基因的转导. Shan 等 ${ }^{[45]}$ 的工作表明金纳 米粒子可以维持树枝状高分子的模板，刚性金纳米粒子 包覆在树枝状高分子的内部有助于保护树枝状分子的 树枝状三维球面，因此具有更多结合 DNA 的位点. 他 们利用五代树枝状分子氨基修饰的 DENPs(树枝状分子) 与金纳米粒子结合能够显著提高树枝状聚合物致密压 缩 DNA 的能力. Au-DENPs 被用作基因载体在体外对不 同细胞系的苂光素酶(Luc)和绿色荧光蛋白(EGFP)均能 高效转载.

石墨烯具有良好的导电、导热性以及电化学稳定性, 石墨烯材料被广泛应用在电化学、生物化学以及材料化 


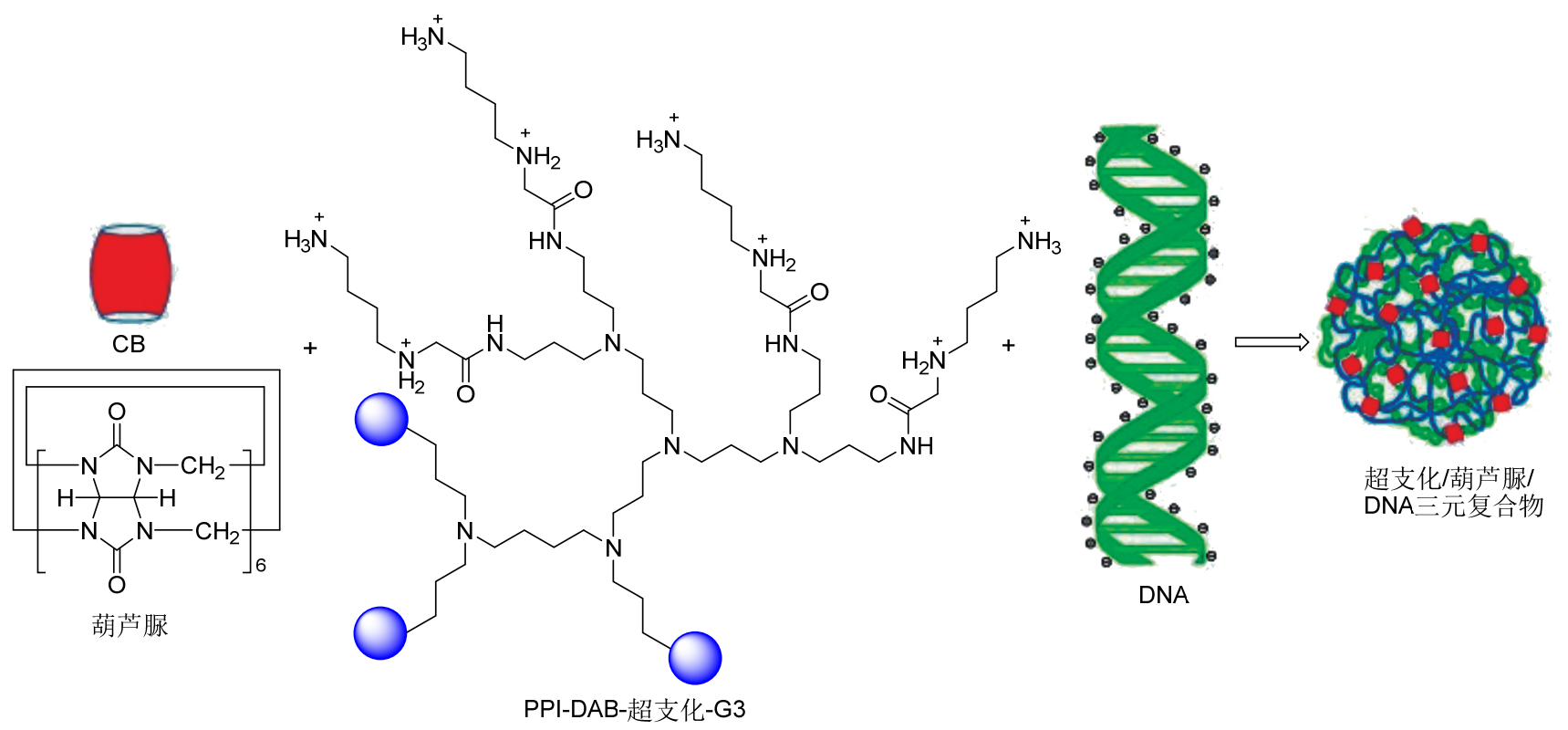

图 13 葫芦脲超支化基因载体

Figure 13 Cucurbituril hyperbranched gene carrier

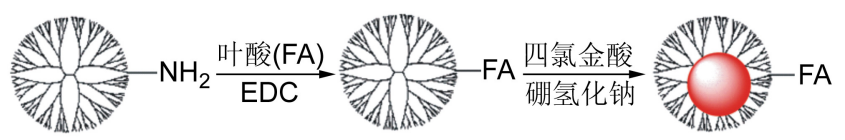

图 14 金纳米颗粒结合的树枝基因载体

Figure 14 Gold nanoparticle binding dendrimer gene carrier 学中. Kim 等 ${ }^{[46]}$ 通过修饰氧化石墨烯的官能团(GO)赋予 其特定的功能或结构属性(如易于控制合成、高水分散 性、良好的胶体稳定性和生物相容性、可调的表面官能 化等). 因此它在生物医学领域如生物分子成像、药物基 因载体和癌症治疗等方面吸引了越来越多的关注. 他们 以 $\mathrm{GO}$ 为基础修饰上低分子量支化聚乙烯亚胺 (BPEI, 一种低分子量阳离子基因载体, 它可提高与 DNA 结合 率和转染效率)形成了有效的基因载体(图 15). 细胞实 验证实了 BPEI-GO 具有较高的转染效率和细胞活力.
此外, GO 的 BPEI 与 GO 之间的共轭效应也增强了 $\mathrm{GO}$ 的光致发光性能, 因此 BPEI-GO 可以作为生物体内的 苂光试剂. Yang 等 ${ }^{[47]}$ 进一步研究在 GO 上嫁接 PAMAM 大分子和镓离子. 在姜黄素对胶质瘤 U87 细胞转载 miRNA 后可以进一步利用石墨烯作荧光共聚显微镜, 用于化疗和核磁共振成像. 这些实验结果表明镓偶联的 树枝状高分子-氧化石墨烯配合物可作为有效的非病毒 基因载体应用于基因转载和肿瘤的治疗.

Holger 等 ${ }^{[48,49]}$ 通过不同单体 [如聚丙烯酸(PAA)]修 饰一步法制备了表面包覆羧基的水溶性磁性纳米颗粒 (PAAIO). 表面带负电荷的磁性纳米粒子可以很容易在 水相中和支化聚乙烯亚胺结合. 修饰上阳离子支化聚乙 烯亚胺后的磁性载体可以与 DNA 结合(图 16). 由于 PEI-PAAIO/pDNA 较低的细胞毒性和良好的稳定性, 其
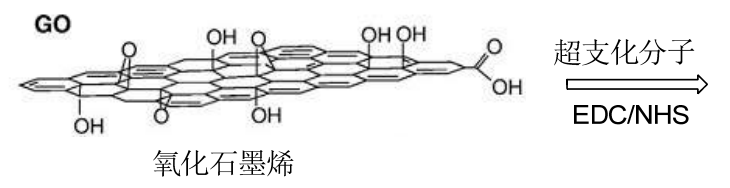<smiles>CNCCN(CCN)CCN</smiles>

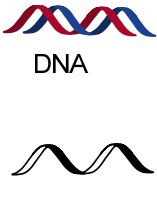

超支化分子

PEG
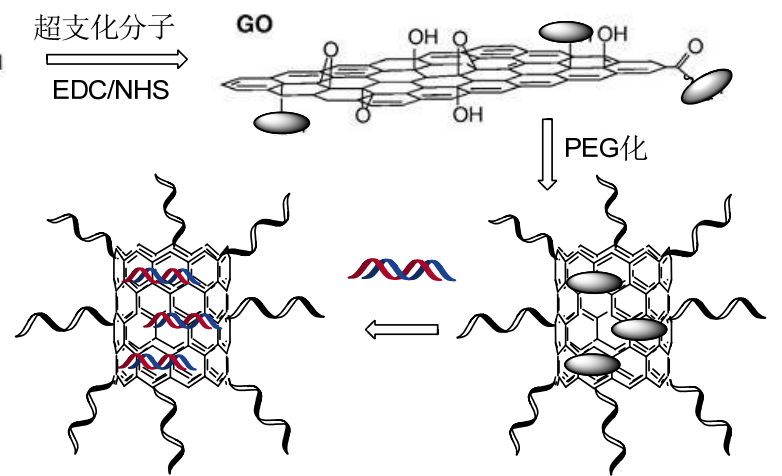

图 15 石墨烯复合的超支化基因载体

Figure 15 Graphene composite hyperbranched gene carrier 


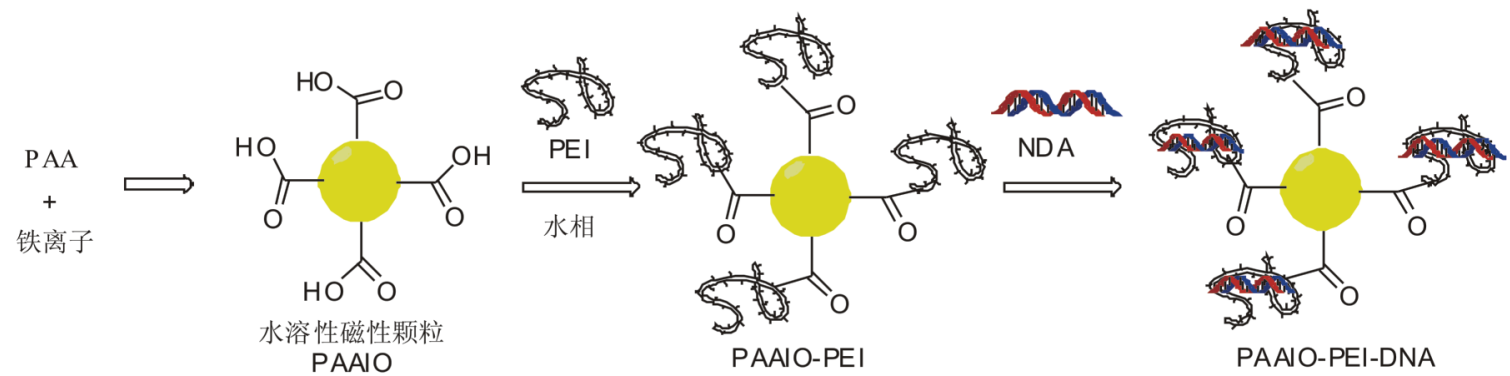

图 16 磁性纳米颗粒结合的超支化基因载体

Figure 16 Magnetic nanoparticle binding hyperbranched gene carrier

作为基因载体和单独的 PEI 和聚合物-磁性颗粒相比更 加优越. 虽然在肽牛血清存在时其基因转导的表达较 低, 但当暴露在磁场中时, PEI-PAAIO/pDNA 的基因转 染效率显著增加. Pan 等 ${ }^{[50]}$ 以 $8 \mathrm{~nm}$ 的超顺磁粒子为基础, 制备了超顺磁一五代聚酰胺-胺树枝状高分子复合物. 该 复合材料在细胞内表现出较高的转染效率. 这些结果表 明, PAMAM 支化分子修饰的超顺磁性纳米颗粒是很好 的基因载体并在癌症治疗以及影像学诊断都有潜在应 用. 溶胶-凝胶法(Sol-Gel 法)同样用于超顺磁-树枝状基 因载体的合成. Gonzale 等 ${ }^{\left[{ }^{11}\right]}$ 以共价键把 PPI 树枝状高分 子接枝到磁赤铁矿纳米粒子 $\left(\gamma-\mathrm{Fe}_{2} \mathrm{O}_{3}\right.$ 纳米颗粒 $)$ 的表面. 利用溶胶一凝胶法用烷氧基硅烷衍生物对铁氧化物纳米 颗粒表面一步修饰上树枝状聚合物. 溶胶一凝胶法合成 的树枝状高分子的功能化的磁性纳米粒子可以形成稳 定的亲水性胶体溶液. 亲水性磁性溶胶的合成有利于磁 性纳米粒子在生物医学中应用.

量子点是在纳米尺度上的原子和分子的集合体, 既 可由一种半导体材料组成, 如由 IIB-VIA 族元素(如 $\mathrm{CdS}, \mathrm{CdSe}, \mathrm{CdTe}, \mathrm{ZnSe}$ 等)或 IIIA-VA 族元素(如 InP, InAs 等)组成, 也可以由两种或两种以上的半导体材料 组成. 作为一种新颖的半导体纳米材料, 量子点具有许 多独特的纳米性质. Endres 等 ${ }^{[52]}$ 报道了两亲性生物可降 解嵌段共聚物 PEG-PCL-PEI 自组装生成的含一个外围 亲水性聚乙二醇( PEG)和内核疏水性聚己内酯(PCL)的 纳米载体. 并且通过调控三个单体的比例可以控制纳米 载体的物化性质. PEG 由于其较好的亲水性降低了生物 毒性, 而支化的 PEI 在亲水疏水核的周围可以很好地复 合核酸. 疏水性内核可以携带疏水性药物以及苂光染料 或量子点. 量子点的核壳结构(如 $\mathrm{CdSe} / \mathrm{ZnS})$ 可以包覆进 聚合物组装的纳米载体疏水层中, 而且亲水层的外延可 以将量子点保持在水溶液中. 量子点较宽的激发波范围 可用于体内体外环境的成像. 三聚复合物 PEG-PCL-PEI 是集治疗成像于一体的多功能纳米基因载体.

\section{4 功能响应性的树枝状聚合物载体}

树枝化聚合物除了在结构式修饰、嵌合得到优良性
质的树枝状基因载体以外，还在功能响应基因载体方面 有着突破性进展. 由于人体内复杂的细胞内外液环境以 及各类生物活性酶的存在, 在体内实现基因转载有很多 障碍. 因此能实现 $\mathrm{pH}$ 或者其他功能响应型的树枝状聚 合物基因载体在临床有更广阔的应用 ${ }^{[53]}$.

Huang 等 ${ }^{[54]}$ 利用谷氨酸和赖氨酸不同的 $\mathrm{p} K_{\mathrm{a}}$ 值, 设 计合成了 $\mathrm{pH}$ 响应型的聚多肽分子. 由于带正电荷的纳 米载体在血液中具有很强的非特征性的细胞摄取能力, 并且与血清发生强烈的相互作用，导致其在体内的严重 沉聚而很快被循环清除，从而限制了其应用(图 17). 基 于以上原因, 他们设计合成了聚谷氨酸-共-赖氨酸的共 聚体, 将其与顺铂络合形成新的肿瘤细胞外 $\mathrm{pH}$ 值触发 的电荷逆转顺铂聚(谷氨酸-共-赖氨酸). 由于共聚物等 电点的影响, 其在血液中 $(\mathrm{pH}=7.4)$ 带负电而具有较长 的半衰期，而在达到癌症区域 $(\mathrm{pH}=6.8)$ 后会转变成带 正电荷的大分子，因而可以提高肿瘤细胞的摄取率. $\mathrm{pH}$ 响应型的超支化分子不仅利于基因的运载，也利于疏水 性药物在体内的释放与吸收. Lakkakula 等 ${ }^{[55]}$ 利用 $\mathrm{pH}$ 引 发缩醛乙酰化 $\alpha$-CD 纳米粒子与紫杉醇自组装形成基因 载体. 在较低的 $\mathrm{pH}$ 值下复合体分解, 释放出紫杉醇. 体 外和体内研究研究证明紫杉醇的运载和基因转载能力 均有较高效率.

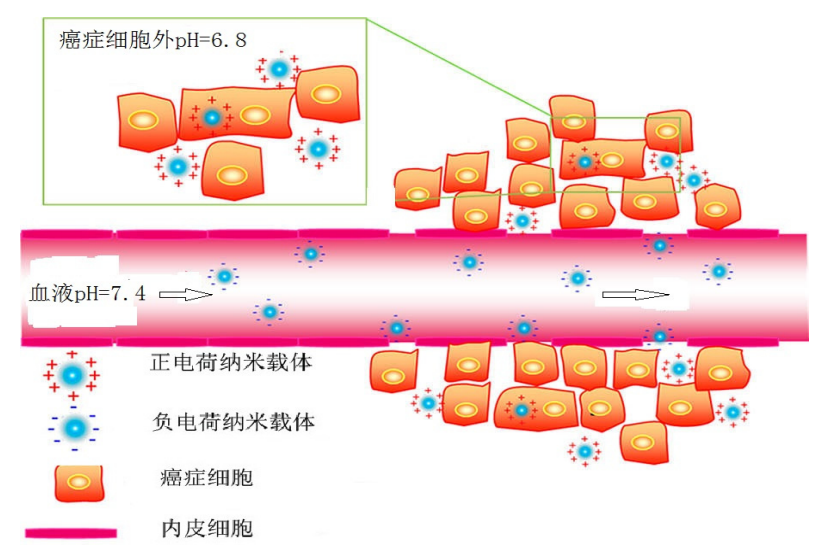

图 $17 \mathrm{pH}$ 响应的基因载体的转导

Figure $17 \mathrm{pH}$ response of the transduction about dendrimer gene carrier 
除了上述的 $\mathrm{pH}$ 响应型基因载体, 利用二硫键响应 的氧化还原型基因载体报道也很多. Ping 等 ${ }^{[56]}$ 制备了一 系列含有二硫键的生物可降解的超支化聚酰胺一胺, 该 高分子以三级胺为核心, 同时利用聚乙二醇、 $N$-氨乙基 哌嗪(AEPZ)进行末端修饰(图 18). 该分子中具有的还原 响应性的二硫键在细胞质中被还原物质迅速降解, 能实 现 DNA 的智能释放, 使得该类双重响应性聚酰胺一胺的 转染效率远高于非响应性的聚酰胺-胺. 原子力显微镜 (AFM) 图显示这种高分子能够与 DNA 复合从而得到稳 定的、带正电荷的粒径为 $50 \sim 200 \mathrm{~nm}$ 的纳米颗粒. 实验 表明 PAA 末端基团结构显著影响基因体外活转染, 而 末端叔胺修饰的 PAA 可以安全高效进行基因传递. Russ 等 ${ }^{\left[{ }^{[7]}\right.}$ 利用叠氮基修饰的聚天冬氨酸-琥珀亚胺为主链物 质, 通过 Click 反应与炔基修饰的双硫键 PEI 分子偶联 得到了聚天冬氨酸基础上的刷状聚乙烯亚胺衍生物. 体 外实验显示该聚合物可以高效压缩 DNA, 被细胞内吞 后, 二硫键在细胞内打开, 迅速释放包覆的 DNA.

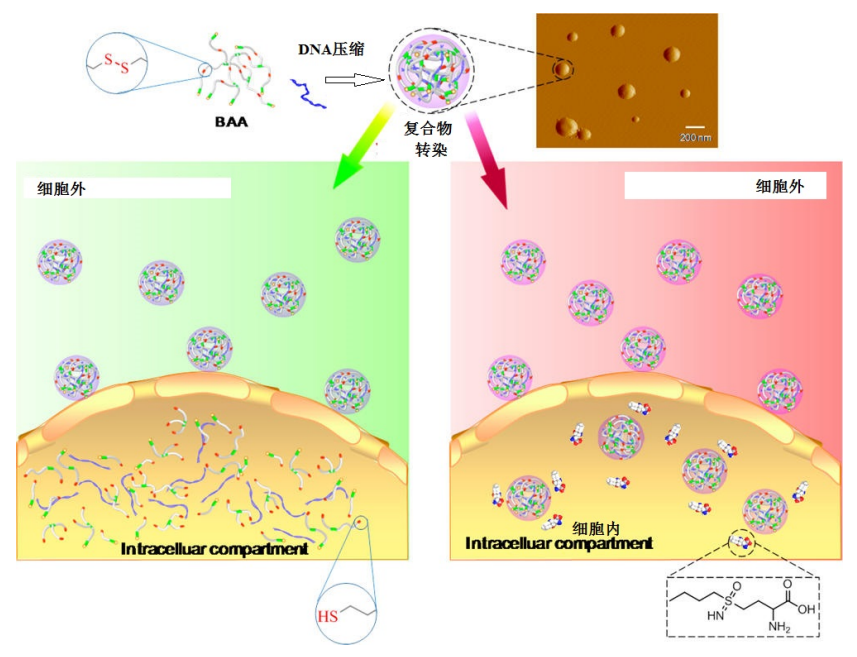

图 18 氧化还原响应型的超支化基因载体的转导

Figure 18 Redox response of the transduction about hyperbranched polymer gene carrier

含氟化合物被广泛地应用在材料、催化以及生物医 学领域中. 由氟修饰的树枝状高分子具有疏水又疏脂的
特殊性质.氟取代的树枝高分子由于其易于合成、卓越的 转染效率和低的细胞毒性为传统树枝状聚合物基因载体 开辟了新的研究领域. 研究表明氟功能化树枝分子可显 著提高细胞摄取率以及内涵体的脱离. Liu 等 ${ }^{[58]}$ 利用五氟 丁酸酐、七氟丁酸䣶和九氟丁基磺酸䣶为氟源将五代 PAMAM 进行氟代化(图 19). 作者进一步利用 YOYO-1 (Y3601)标记的 DNA[同时利用 Lyso-Tracker Red(溶酶体 红色荧光探针)标记的内涵体]在 HeLa 细胞中进行细胞转 染，共聚焦显微镜(白色箭头)显示 YOYO-1 标记的 DNA 在细胞内涵体中出现. 实验表明氟代化的 PAMAM 树枝 高分子作为基因载体在人体肾脏上皮细胞(HEK293 细 胞)和宫颈癌细胞( HeLa 细胞)中的应用均取得很好转载 效率(90\%). 氟代化的树枝状高分子可以极大地提高基因 载体的细胞转染效率并降低细胞毒性. 后期研究结果表 明氟代化的三、四、五代聚(丙烯亚胺)(PPI)在体外细胞转 染中也表现出很好的效率.

\section{6 总结和展望}

综上所述，基于树枝状聚合物及其衍生物在体内体 外多种细胞组织实现了高效基因转载, 可以实现靶向性 以及多功能抗癌治疗. 基于树枝状聚合物基因载体由于 树枝高分子/超支化分子具有无基因尺寸限制、可大量生 产且产品质量重复性好、价格低、使用简单方便、易于 修饰、灵活多变等优点而受到研究者的广泛关注. 树枝聚 合物基因载体为未来非病毒载体的发展开拓了新的领域.

虽然传统型的树枝状聚合物基因载体应用广泛，不 同类别的树枝分子各有所长, 并在不同肿瘤细胞中发挥 基因治疗作用，特别是氨基酸及多肽的修饰，实现了在 特定细胞或体内组织的转染靶向性. 但是他们本身的生 物毒性和细胞相容性限制了其发展, 所以需要对树枝高 分子进行化学修饰以弥补其本身的不足. 通过对树枝高 分子的修饰，可以增加细胞的摄取率，提高其在生物体 内转染基因的效率，拓展了树枝高分子在基因治疗中的 应用范围. 超分子母体材料的修饰提高了树枝聚合物的 细胞膜穿透力, 并且可以构建不同拓扑结构的智能基因
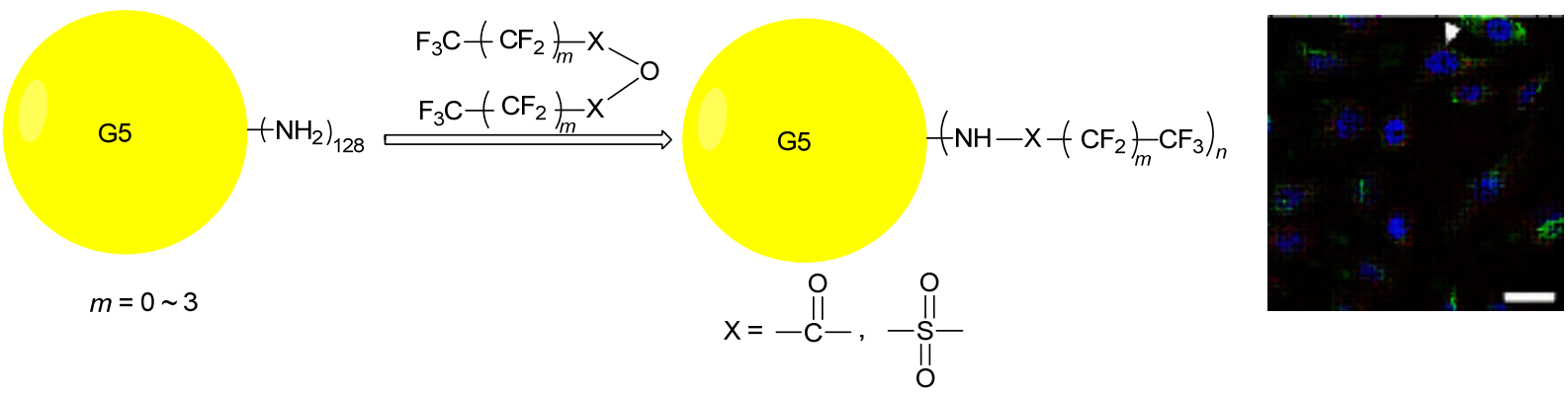

图 19 氟修饰的树枝基因载体

Figure 19 Fluorinated dendrimer gene carrier 
载体; 并且超分子母体材料疏水性的内腔可以包结脂溶 性药物, 实现多功能基因治疗. 但是超分子母体材料本 身需要进行单取代、多取代等官能团修饰后才能与树枝 高分子结合. 而且除了天然的环糊精外, 其他的超分子 母体材料都是需要繁杂的有机合成步骤合成进行, 使其 应用受限. 无机物的修饰赋予树枝状聚合物新的性质, 使得多功能型基因载体应运而生. 然而无机物本身容易 在体内产生抗原抗体反应, 必须经过修饰处理形成水溶 性/生物相容性等才能在体内进行安全基因治疗. 而功 能响应型的树枝状聚合物基因载体, 如 $\mathrm{pH}$ 响应、二硫 键响应可以提高血清抵抗性及细胞相容性. 氟功能化树 枝分子提高了细胞摄取率以及内涵体的脱离. 但是目前 关于功能响应的树枝基因载体在体内体外的转染的临 床治疗工作还是比较缺乏. 总之, 树枝状聚合物通过物 理或化学方法将多种有机无机材料结合在一起进行多 功能疗法, 该疗法中采用了抗癌药物、靶向配体、显像 剂等相结合的方式. 这将打开安全有效多功能抗肿瘤靶 向基因治疗的大门.

非病毒载体包括阳离子脂质体、树枝状聚合物和多 肽都为基因载体提供了新途径. 不少病毒载体的基因治 疗实现了从实验室进入临床试验过程, 已经批准的基因 治疗临床试验方案有数千项, 其中大部分都是针对恶性 肿瘤的治疗, 但是安全转载效率高的非病毒载体的需求 仍然迫切. 而树枝状聚合物基因载体临床治疗工作还是 比较少. 树枝聚合物的引入可以很好地构建多种构型的 基因载体, 为载体的功能化和靶向型提供更多的选择 性. 随着对树枝状聚合物分子的深入研究, 树枝状聚合 物分子在基因转载上的运用会越来越广泛. 以树枝状聚 合物为基础的树枝状聚合物基因药物输送和基因运载 作为临床上可行的抗癌疗法将会得到越来越多科学家 的亲睐.

\section{References}

[1] Malhotra, S.; Bauer, H.; Tschiche, A.; Staedtler, A. M.; Mohr, A.; Calderon, M.; Parmar, V. S.; Hoeke, L.; Sharbati, S.; Einspanier, R.; Haag, R. Biomacromolecules 2012, 13, 3087.

[2] Zeng, H.-X.; Timothy, N. T.; Little, H. C.; Tiambeng, T. N.; Williams, G. A.; Guan, Z. B. J. Am. Chem. Soc. 2013, 135, 4962.

[3] Kolli, S.; Wong, S. P.; Harbottle, R.; Johnston, B.; Thanou, M.; Miller, A. D. Bioconjugate Chem. 2013, 24, 314.

[4] Liu, C.; Liu, X.-X.; Rocchi, P.; Qu, F.-Q.; Iovanna, J. L.; Peng, L. Bioconjugate Chem. 2014, 25, 521.

[5] Liu, H.-M.; Wang, H.; Yang, W.-J.; Cheng, Y. Y. J. Am. Chem. Soc. 2012, 134, 17680 .

[6] Jones, C. H.; Chen, C.-K.; Jiang, M.; Fang, L.; Cheng, C.; Pfeifer, B. A. Mol. Pharm. 2013, 10, 1138.

[7] Guo, X.; Huang, L. Acc. Chem. Res. 2012, 45, 971.

[8] Tarwadi; Jazayeri, J. A.; Prankerd, R. J.; Pouton, C. W. Bioconjugate Chem. 2008, 19, 940.

[9] Jia, H.-Z.; Zhang, W.; Wang, X.-L.; Yang, B.; Chen, W.-H.; Chen,
S.; Chen, G.; Zhao, Y.-F.; Zhuo, R.-X.; Feng, J.; Zhang, X.-Z. Biomater. Sci. 2015, 3, 1066.

[10] Motoyama, K.; Hayashida, K.; Higashi, T.; Arima, H. Bioorg. Med. Chem. 2012, 20, 1425

[11] Al-Deen, F. N.; Ho, J.; Selomulya, C.; Ma, C.; Coppel, R. Langmuir 2011, 27, 3703.

[12] Tabassi, S. A. S.; Tekie, F. S. M.; Hadizadeh, F.; Rashid, R.; Khodaverdi, E.; Mohajeri, S. A. J. Sol.-Gel. Sci. Technol. 2014, 69, 166.

[13] Zhou, Z.-X.; Ma, X.-P.; Jin, E.-L.; Tang, J.-B.; Sui, M.-H.; Shen, Y.-Q.; Van Kirk, E. A.; Murdoch, W. J.; Radosz, M. Biomaterials 2013, 34, 5722 .

[14] Jia, H.-Z.; Zhang, W.; Zhu, J.-Y.; Yang, B.; Chen, S.; Chen, G.; Zhao, Y.-F.; Feng, J.; Zhang, X.-Z. J. Controlled Release 2015, 216, 9.

[15] (a) Tao, W.; Liu, Y.; Jiang, B.-B.; Yu, S.-R.; Huang, W.; Zhou, Y.-F.; Yan, D.-Y. J. Am. Chem. Soc. 2012, 134, 762.

(b) Liu, Y.; Yu, C.-Y.; Jin, H.-B.; Jiang, B.-B.; Zhu, X.-Y.; Zhou, Y.-F.; Lu, Z.-Y.; Yan, D.-Y. J. Am. Chem. Soc. 2013, 135, 4765.

(c) Yan, D.-Y.; Zhou, Y.-F.; Hou, J. Science 2004, 303, 65.

(d) Zhou, Y.-F.; Yan, D.-Y. Angew. Chem., Int. Ed. 2004, 43, 4896.

(e) Liu, C.-H.; Gao, C.; Yan, D.-Y. Angew. Chem., Int. Ed. 2007, 46, 4128.

(f) Olga, Y.-Z.; Xu, L.-Y.; Kristoffer, V.; Yang, H. RSC. Adv. 2015, 5, 58600 .

(g) Zhou, Y.-F.; Yan, D.-Y. Chem. Commun. 2009, 1172.

(h) Zhou, Y.-F.; Huang, W.; Liu, J.-Y.; Zhu, X.-Y.; Yan, D. Y. Adv Mater. 2010, 22, 4567.

(i) Zhou, Y.-F.; Yan, D.-Y. J. Am. Chem. Soc. 2005, 127, 10468.

(j) Jin, H.-B.; Zheng, Y.-L.; Liu, Y.; Cheng, H.-X.; Zhou, Y.-F.; Yan, D.-Y. Angew. Chem., Int. Ed. 2011, 50, 10352.

(k) Liu, J.-Y.; Huang, W.; Yan, D.-Y.; Pang, Y.; Huang, P.; Zhu, X.-Y.; Zhou, Y.-F. Angew. Chem., Int. Ed. 2011, 50, 9162.

(1) Xu, W.-N.; Liu, M.-Y.; Hong, S.-B.; Yan, W.; Fu, J.-F.; Deng, W. Prog. Chem. 2014, 26, 375 (in Chinese).

(徐妮为, 刘梦艳, 洪诗斌, 颜蔚, 付继芳, 邓维, 化学进展, 2014, 26, 375.)

[16] (a) Cheng, Y.-Y.; Xu, Z.-H.; Ma, M.-L.; Xu, T.-W. J. Pharm. Sci. 2008, 97, 123.

(b) Tomalia, D. A.; Frchet, J. M. J. J. Polym. Sci. Part A, Polym. Chem. 2002, 40, 2719

[17] (a) Yang, J.-P.; Zhang, Q.; Chang, H.; Cheng, Y.-Y. Chem. Rev. 2015, 115, 5274 .

(b) He, D.-S.; Wagner, E. Macromol. Biosci. 2015, 15, 600.

(c) Kesharwani, P.; Lyer, A. K. Drug Discovery Today 2015, 20 , 536.

(d) Somani, S.; Dufes, C. Nanomedicine 2015, 9, 2403.

[18] (a) Chen, K.-H.; Li, X.; Gu, H.-C. J. Mater. Sci. Eng. 2013, 30, 306 (in Chinese).

(陈开花, 李旭, 古宏晨，材料科学与工程学报, 2013, 30, 306.)

(b) Morales-Sanfrutos, J.; Megia-Fernandez, A.; Hernandez-Mateo, F.; Giron-Gonzalez, M. D.; Salto-Gonzalez, R.; Santoyo-Gonzalez, F. Org. Biomol. Chem. 2011, 9, 851.

(c) Menighan, T. E. J. Pharm. Sci.-US 2011, 100, 6.

(d) Nam, K.; Jung, S.; Nam, J. P.; Kim, S. W. J. Controlled Release 2015, 220, 447.

(e) Seib, F. P.; Jones, A. T.; Duncan, R. J. Controlled Release 2007, $117,291$.

(f) Kea, W. L.; Shao, K.; Jiang, C.; Huang, R.-Q.; Han, L.; Liu, Y.; Li, J.-F.; Kuang, Y.-Y.; Ye, L. Y.; Lou, J. N. Biomaterials 2009, 30, 6976.

(g) Huang, S.-X.; Li, J.-F.; Jiang, C.; Han, L.; Liu, S.-H.; Ma, H.-J.; 
Huang, R.-Q.; Jiang, C. Biomaterials 2011, 32, 6832.

(h) Gerard, H.-C.; Mishra, M.-K.; Mao, G.-Z.; Wang, S.-X.; Hali, M.; Whittum-Hudson, J. A.; Kannan, R. M.; Hudson, A. P. Nanomed.-Nanotechnol. Biol. Med. 2013, 9, 996.

(i) Yu, G.-S.; Yu, H.-N.; Choe, Y.-H.; Son, S.-J.; Ha, T.-H.; Choi, J.-S. Bull. Korean Chem. Soc. 2011, 32, 651.

(j) Aldawsari, H.; Edrada-Ebel, R.; Blatchford, D. R.; Tate, R. J.; Tetley, L.; Dufes, C. Biomaterials 2011, 32, 5889.

(k) Wen, Y.-T.; Guo, Z.-H.; Pan, S.-R.; Wen, Y.-T.; Guo, Z.-H.; Du, Z.; Fang, R.; Wu, H. M.; Zeng, X.; Wang, C.; Feng, M.; Pan, S.-R. Biomaterials 2012, 33, 8111.

(1) Kwon, M. J.; An, S.; Choi, S.; Nam, K.; Jung, H. S.; Yoon, C. S.; Ko, J. H.; Jun, H. J.; Kim, T. K.; Jung, S. J.; Park, J. H.; Lee, Y.; Park, J. S. J. Gene Med. 2012, 14, 272.

(m) An, S.; Nam, K.; Choi, S.; Bai, C. Z.; Lee, Y.; Park, J. S. Int. J. Nanomed. 2013, 8, 821.

(n) Biswas, S.; Deshpande, P. P.; Navarro, G.; Dodwadkar, N. S.; Torchilin, V. R. Biomaterials 2013, 34, 1289.

(o) Wu, H.-M.; Pan, S.-R.; Chen, M.-W.; Wu, Y.; Wang, C.; Wen, Y.-T.; Zeng, X.; Wu, C.-B. Biomaterials 2011, 32, 1619.

(p) Han, L.-A.; Huang, R.-Q.; Li, J.-F.; Liu, S.-H.; Huang, S.-X.; Jiang, C. Biomaterials 2011, 32, 1242.

[19] Green, J.-J.; Langer, R.; Anderson, D. G. Acc. Chem. Res. 2008, 6, 749.

[20] Carsten, R.; Markus, E; Corinna, P.; Senta, U.; Monika, M. G.; Bjoern, S.; Christof, M.; Holger, S.; Manish, K. A. Biomacromolecules 2009, 10, 2912.

[21] (a) Lo, Y.-L.; Sung, K.-H.; Chiu, C.-C.; Wang, L.-F. Mol. Pharm. 2013, 10, 664 .

(b) Steele, T. W. J.; Shier, W. T. Pharm. Res.-Doror. 2010, 27, 683.

(c) Lampela, P.; Soininen, P.; Urtti, A.; Mannisto, P. T.; Raasmaja, A. Int. J. Pharm. 2004, 270, 175.

(d) Li, Y.-P.; Xiao, J.-S.; Duan, X.-P.; Xiao, J.-S.; Duan, X.-P.; Yin, Q.; Chen, L.-L.; Zhang, Z.-W. Bioconjugate Chem. 2012, 23, 222.

[22] (a) Wang, R.-B.; Zhou, L.-Z.; Zhou, Y.-F.; Li, G.-L.; Zhu, X.-Y.; Gu, H.-C.; Jiang, X.-L.; Li, H.-Q.; Wu, J.-L.; He, L.; Guo, X.-Q.; Zhu, B.-S.; Yan, D.-Y. Biomacromolecules 2010, 11, 489.

(b) Vander Aa, L. J.; Vader, P.; Storm, G.; Schiffelers, R. M.; Engbersen, J. F. J. J. Controlled Release 2011, 150, 177.

[23] Thankappan, U. P.; Madhusudana, S. N.; Desai, A.; Jayamurugan, G.; Rajesh, Y. B. R. D.; Jayaraman, N. Bioconjugate Chem. 2011, $22,115$.

[24] (a) Lee, J.; Jung, J.; Kim, Y. J.; Lee, E.; Choi, J. S. Int. J. Pharm. 2014, 459, 10 .

(b) Li, H.-M.; Sun, X.; Zhao, D.; Zhang, Z.-R. Mol. Pharm. 2012, 9, 2974.

[25] (a) Zarebkohan, A.; Najafi, F.; Moghimi, H. R.; Hemmati, M.; Deevband, M. R.; Kazemi, B. Eur. J. Pharm. Sci. 2015, 78, 19.

(b) Guan, L.-M.; Huang, S.-P.; Chen, Z.; Li, Y.-C.; Liu, K.; Liu, Y.; Du, L.-B. J. Nanopart. Res. 2015, 17, 385.

(c) Hwang, M. E.; Keswani, R. K.; Pack, D. W. Pharm. Res. 2015, 32, 2051.

(d) Wang, K.; Hu, Q.-D.; Zhu, W.; Zhao, M.-M.; Ping, Y.; Tang, G.-P. Adv. Funct. Mater. 2015, 25, 3380.

(e) Mishra, M. K.; Gerard, H. C.; Whittum-Hudson, J. A.; Hudson, A. P.; Kannan, R. M. Mol. Pharm. 2012, 9, 413.

(f) Liu, X.-X.; Wu, J.-Y.; Yammine, M.; Zhou, J.-H.; Posocco, P.; Viel, S.; Liu, C.; Ziarelli, F.; Fermeglia, M.; Pricl, S.; Victorero, G.; Catherine, N.; Erbacher, P.; Behr, J. P.; Peng, L. Bioconjugate Chem. 2011, 22, 2461.

(g) Yu, T.-Z.; Liu, X.-X.; Bolcato-Bellemin, A. L.; Wang, Y.; Liu, C.; Erbacher, P.; Qu, F. Q.; Rocchi, P.; Behr, J. P.; Peng, L. Angew.
Chem., Int. Ed. 2012, 51, 8478.

[26] Sarkar, K.; Kundu, P. P. Carbohydr. Polym. 2013, 98, 495.

[27] Zhang, X.-Y.; Zhao, J.; Yao, F.-L.; Wen, Y.; Zhu, C. S.; Yang, J.; Yao, F. L. Carbohydr. Polym. 2013, 98, 1326.

[28] (a) Tamara, M.; Mahesh L, P.; Zhang, M. ACS nano 2011, 5, 1877. (b) Liu, L.; Zheng, M. Y.; Renette, T.; Kissel, T. Bioconjugate Chem. 2012, 23, 1211.

[29] (a) Zhang, X.; Hu, H.-M.; Liu, T.-B.; Yang, Y.-Y.; Peng, Y.-F.; Cai, Q.-Q.; Fang, L.-J. Int. J. Pharm. 2014, 465, 444.

(b) Dai, J.; Zou, S.-Y.; Pei, Y.-Y.; Cheng, D.; Ai, H.; Shuai, X.-T. Biomaterials 2011, 32, 1694.

(c) Liu, K.-L.; Xu, Z.-J.; Yin, M.-Z. Prog. Polym. Sci. 2015, 46, 25.

[30] (a) Wang, Y.; Li, L.; Shao, N.-M.; Hu, Z.-Q.; Chen, H.; Xu, L.-Q.; Wang, C.-P.; Cheng, Y.-Y.; Xiao, J.-R. Acta Biomater. 2015, 17, 115.

(b) Merkel, O. M.; Mintzer, M. A.; Librizzi, D.; Samsonova, O.; Dicke, T.; Sproat, B.; Garn, H.; Barth, P. J.; Simanek, E. E.; Kissel, T. Mol. Pharm. 2010, 7, 969.

[31] Shao, N.-M.; Wang, H.; He, B.-W.; Wang, Y.; Xiao, J.-R.; Wang, Y.-T.; Zhang, Q.; Lia, Y-. J.; Cheng, Y.-Y. Biomater. Sci. 2015, 3 , 500 .

[32] (a) Martinez, A.; Fuentes-Paniagua, E.; Baeza, A.; Sanchez-Nieves, J.; Cicuendez, M.; Gomez, R.; de la Mata, F. J.; Gonzalez, B.; Vallet-Regi, M. Chem. Eur. J. 2015, 21, 15651.

(b) Fornaguera, C.; Grijalvo, S.; Galan, M.; Fuentes-Paniagua, E.; de la Mata, F. J.; Gomez, R.; Eritja, R.; Caldero, G.; Solans, C. Int. J. Pharm. 2015, 418, 113.

(c) Gras, R,; Almonacid, L.; Ortega, P.; Serramia, M. J.; Gomez, R.; de la Mata, F. J.; Lopez-Fernandez, L.; Munoz-Fernandez, M. A. Pharm. Res. 2009, 26, 577.

[33] (a) Loup, C.; Zanta, M. A.; Caminade, A. M.; Majoral, J. P.; Meunier, B. Chem. Eur. J. 1999, 5, 3644.

(b) Fraix, A.; Montier, T.; Carmoy, N.; Loizeau, D.; Burel-Deschamps, L.; Le Gall, T.; iamarchi, P.; Couthon-Gourves, H.; Haelters, J. P.; Lehn, P. Org. Biomol. Chem. 2011, 9, 2422.

(c) Ferenc, M.; Pedziwiatr-Werbicka, E.; Nowak, K. E.; Klajnert, B.; Majoral, J. P.; Bryszewska, M. Molecules 2013, 18, 4451.

[34] (a) Li, J.; Lepadatu, A. M.; Zhu, Y.; Ciobanu, M.; Wang, Y.; Asaftei, S. C.; Oupicky, D. Bioconjugate Chem. 2014, 25, 907.

(b) Yang, H.; Miyoshi, H.; Lou, C.; Ren, Z.; Liu, Y. Chin. Sci. Bull. 2010, 55, 263.

[35] (a) Pandita, D.; Santos, J. L.; Rodrigues, J.; Pego, A. P.; Granja, P. L.; Tomas, H. Biomacromolecules 2011, 12, 472.

(b) Park, H.-W.; Yu, G.-S.; Song, S.-J.; Choi, J.-S. Polymer-Korea 2015, 39, 727 .

(c) Zhao, J.-J.; Zhang, B.; Shen, S.; Chen, J.; Zhang, Q.-Z.; Jiang, X.-G.; Pang, Z.-Q. J. Colloid Interface Sci. 2015, 450, 396.

(d) Li, X.; Xie, Z.-X.; Xie, C.; Lu, W.-Y.; Gao, C.-L.; Ren, H.-L.; Ying, M.; Wei, X.-L.; Gao, J.; Su, B.-X. Bioconjugate Chem. 2015, 26,1494 .

(e) Luo, K.; He, B.; Wu, Y.; Shen, Y.-Q.; Gu, Z.-W. Biotechnol. Adv. 2014, 32, 818 .

(f) Ohsaki, M.; Okuda, T.; Wada, A.; Hirayama, T.; Niidome, T.; Aoyagi, H. Bioconjugate Chem. 2002, 13, 510.

(g) Yingyongnarongkul, B.; Howarth, M.; Elliott, T.; Bradley, M. J. Comb. Chem. 2004, 6, 753.

(h) Lian, G. P.; Malone, M. E.; Homan, J. E.; Norton, I. T. J. Controlled Release 2004, 99, 139.

(i) Bansal, R.; Singh, M.; Gupta, K. C.; Kumar, P. Biomater Sci. 2014, 2, 1275 .

(j) Kono, K.; Akiyama, H.; Takahashi, T.; Takagishi, T.; Harada, A. Bioconjugate Chem. 2005, 16, 208. 
(k) Coles, D. J.; Yang, S.; Esposito, A.; Mitchell, D.; Minchin, R. F.; Toth, I. Tetrahedron 2007, 63, 12207.

(1)Yang, Y.; Lee, J.; Cho, M.; Sheares, V. V. Macromolecules 2006, 39,8625 .

[36] Khuloud, T. A. J.; Wafa, T. A. J.; Julie, T. W. W.; Noelia, R.; Joanna, B.; David, G. M. Z.; Kostas, K. ACS Nano 2013, 7, 1905.

[37] Bayele, H. K.; Sakthivel, T.; O'Donell, M.; Pasi, K. J.; Wilderspin, A. F.; Lee, C. A.; Toth, I.; Florence, A. T. J. Pharm. Sci.-US 2005, $94,446$.

[38] (a) Motoyama, K.; Mitsuyasu, R.; Akao, C.; Abu Hashim, I. I.; Sato, N.; Tanaka, T.; Higashi, T.; Arima, H. Mol. Pharm. 2015, 12, 3129 .

(b) Zhang, J.-X.; Sun, H.-L.; Ma, P.-X. ACS Nano 2010, 4, 1049.

(c) Tong, H.-J.; Wang, C.-D.; Huang, Y.; Shi, Q.; Fernandes, J. C.; Dai, K.-R.; Tang, G.-P.; Zhang, X.-L. Int. J. Nanomed. 2013, 8, 1935.

(d) Ang, C.-Y.; Tan, S.-Y.; Wang, X.-L.; Zhang, Q.; Khan, M.; Bai, L.-Y.; Selvan, S.-T.; Ma, X.; Zhu, L-L.; Nguyen, K. T. J. Mater. Chem. B 2014, 2, 1879.

(e) Arima, H.; Yoshimatsu, A.; Ikeda, H.; Ohyama, A.; Motoyama, K.; Higashi, T.; Tsuchiya, A.; Niidome, T.; Katayama, Y.; Hattori, K. Mol. Pharm. 2012, 9, 2591.

(f) Pun, S. H.; Bellocq, N. C.; Liu, A. J.; Jensen, G.; Machemer, T.; Quijano, E.; Schluep, T.; Wen, S. F.; Engler, H.; Heidel, J.; Davis, M. E. Bioconjugate Chem. 2004, 15, 831.

(g) Forrest, M. L.; Gabrielson, N.; Pack, D. W. Biotechnol. Bioeng. 2005, 89,416

(h) Wada, K.; Arima, H.; Tsutsumi, T.; Hirayama, F.; Uekama, K. Biol. Pharm. Bull. 2005, 28, 500.

(i) Arima, H.; Chihara, Y.; Arizono, M.; Yamashita, S.; Wada, K.; Hirayama, F.; Uekama, K. J. Controlled Release 2006, 116, 64.

(j) Hayashi, Y.; Mori, Y.; Yamashita, S.; Motoyama, K.; Higashi, T.; Jono, H.; Ando, Y.; Arima, H. Mol. Pharm. 2012, 9, 1645.

[39] Shreyas, S.; Aniruddh, S.; Pijus, K. S.; Ki-Bum, L. J. Am. Chem. Soc. 2013, 135, 15682 .

[40] Huang, H.; Cao, D.-W.; Qin, L.-H.; Tian, S.-Q.; Liang, Y.; Pan, S.-R.; Feng, M. Mol. Pharm. 2014, 11, 2323.

[41] Lim, Y. B.; Kim, T.; Lee, J. W.; Kim, S. M.; Kim, H. J.; Kim, K.; Park, J. S. Bioconjugate Chem. 2002, 13, 1181.

[42] (a) Hou, W.-X.; Wen, S.-H.; Guo, R.; Wang, S.-G. J. Nanosci. Nanotechnol. 2015, 15, 4094.

(b) Du, X.; Shi, B.-Y.; Liang, J.; Bi, J.-X.; Dai, S.; Qiao, S.-Z. Adv. Mater. 2013, 25, 5981.

(c) Guerra, J.; Herrero, M. A.; Carrion, B.; Perez-Martinez, F. C.; Lucio, M.; Rubio, N.; Meneghetti, M.; Prato, M.; Cena, V.; Vazquez, E. Carbon 2012, 50, 2832.

(d) Guerra, J.; Herrero, M. A.; Vazquez, E. RSC $A d v$. 2014, 4, 27315.

[43] Shi, X.-Y.; Xiao, T.-Y.; Hou, W.-X.; Cao, X.-Y.; Wen, S.-H.; Shen, M.-W. Biomater. Sci. 2013, 1, 1172.

[44] (a) Byrne, M.; Victory, D.; Hibbitts, A.; Lanigan, M.; Heise, A.; Cryan, S. A. Biomater. Sci. 2013, 1, 1223.

(b) Figueroa, E. R.; Lin, A. Y.; Yan, J. X.; Luo, L.; Foster, A. E.;
Drezek, R. A. Biomaterials 2014, 35, 1725.

[45] Shan, Y.-B.; Luo, T.; Shi, X.-Y.; Peng, C.; Sheng, R.-L.; Cao, A.-M.; Cao, X.-Y.; Shen, M.-W.; Guo, R.; Tomas, H. Biomaterials 2012, 33, 3025.

[46] Kim, H.; Kim, W. J. Small 2014, 1, 117.

[47] Yang, H. W.; Huang, C.-Y.; Chen C.-M.; Liu, H.-L.; Huang, C.-W.; Liao, S.-S.; Chen, P.-Y.; Lu, Y.-J.; Wei, K.-C.; Ma, C.-M. Biomaterials 2014, 35, 6534.

[48] Majewski, A. P.; Schallon, A.; Jerome, V.; Freitag, R.; Muller, A. H. E.; Schmalz, H. Biomacromolecules 2012, 13, 857.

[49] Taratula, O.; Garbuzenko, O.; Savla, R.; Wang, Y. A.; He, H. X.; Minko, T. Curr. Drug Delivery 2011, 8, 59.

[50] Pan, B. F.; Cui, D. X.; Sheng, Y.; Cengiz, O.; Gao, F.; He, R.; Li, Q.; Xu, P.; Huang, T. Cancer Res. 2007, 67, 8156.

[51] Gonzalez, B.; Ruiz-Hernandez, E.; Feito, M. J.; de Laorden, C. L.; Arcos, D.; Ramirez-Santillan, C.; Matesanz, C.; Portoles, M. T.; Vallet-Regi, M. J. Mater. Chem. 2011, 21, 4598.

[52] Endres, T.; Zheng, M. Y.; Kilic, A.; Turowska, A.; Beck-Broichsitter, M.; Renz, H.; Merkel, O. M.; Kissel, T. Mol. Pharm. 2014, 11, 1273.

[53] (a) Kim, S. H.; Madak-Erdogan, Z.; Bae, S. C.; Carlson, K. E.; Mayne, C. G.; Granick, S.; Katzenellenbogen, B. S.; Katzenellenbogen, J. A. J. Am. Chem. Soc. 2015, 137, 10326.

(b) Nam, J. P.; Nam, K.; Jung, S.; Nah, J. W.; Kim, S. W. J. Controlled Release 2015, 209, 179.

(c) Dong, C.-Y.; Dong, H.-Q.; Wang, G.-M.; Pauletti, G. M.; Pan, X. J.; Wen, H. Y.; Mehl, I.; Li, Y. Y.; Shi, D. L. Biomacromolecules 2012, 13, 1024.

(d) Nam, H. Y.; Nam, K.; Lee, M.; Kim, S. W.; Bull, D. A. J. Controlled Release 2012, 160, 592.

(e) Tai, Z.-G.; Wang, X.-Y.; Tian, J.; Gao, Y.; Zhang, L.-J.; Yao, C.; Wu, X.; Zhang, W.; Zhu, Q.-G.; Gao, S. Biomacromolecules 2015, 16,1119

[54] Huang, Y.; Tang, Z. H.; Zhang, X.-F.; Yu, H.-Y.; Sun, H.; Pang, X. Biomacromolecules 2013, 14, 2023.

[55] Lakkakula, J. R.; Krause, R. W. M. Nanomedicine 2014, 9, 877.

[56] (a) Ping, Y.; Wu, D.-C.; Kumar, J. N.; Cheng, W.-R.; Lay, C. L.; Liu, Y. Biomacromolecules 2013, 14, 2083.

(b) Zhang, B.; Ma, X.-P.; Shen, Y.-Q. Murdoch, W.; Radosz, M.; Shen, Y.-Q. Biotechnol. Bioeng. 2013, 110, 990.

(c) Li, M.-Y.; Zhou, X.-Y.; Zeng, X.-L.; Wang, Y.-Y.; Xu, J.-K.; Ma, D.; Xue, W. J. Mater. Chem. B 2016, 4, 547.

[57] Russ, V.; Gunther, M.; Halama, A.; Ogris, M.; Wagner, E. J. Controlled Release 2008, 132, 131.

[58] (a) Wang, M.-M.; Cheng, Y.-Y. Biomaterials. 2014, 35, 6603.

(b) Liu, H.-M.; Wang, Y.; Wang, M.-M.; Xiao, J.-R.; Cheng, Y.-Y. Biomaterials 2014, 35, 5407.

(c) Wang, M.-M.; Liu, H.-M.; Li, L.; Cheng, Y.-Y. Nat. Commun. 2014, 5, 3053.

(d) Wang, H.; Wang, Y.-T.; Wang, Y.; Hu, J.-J.; Li, T.-F.; Liu, H.-M.; Zhang, Q.; Cheng, Y.-Y. Angew. Chem., Int. Ed. 2015, 54, 11647. 